Review article

Section: Food Technology

\title{
Crossroad of Tradition and Innovation - The Application of Lactic Acid Fermentation to Increase the Nutritional and Health-Promoting Potential of Plant-Based Food Products - a Review
}

\author{
Anna Maria Ogrodowczyk ${ }^{\circledR}$, Natalia Drabińska ${ }^{\circledR}$ * \\ Division of Food Sciences, Institute of Animal Reproduction and Food Research of the Polish Academy of Sciences, \\ Tuwima 10, 10-747 Olsztyn, Poland
}

Key words: fermentation, lactic acid fermentation, lactic acid bacteria, plant food, fermented food

Lactic acid (LA) fermentation of plant-based products is a commonly used process all over the world. Recently, except for extending the shelf-life of food and improving its palatability, the popularity of fermented food increased because of their nutritional and health-promoting quality. In this review, the existing knowledge about the effects of LA fermentation in different types of plant-based food matrices on their nutritive and health-promoting potential is presented and discussed based on the most recent studies. Furthermore, the toxicological and unfavorable effects are addressed.

This review shows that although the biotransformation of several nutrients and bioactive compounds and the strain-dependent properties need more in-depth elucidation in several matrices, the recently published studies proved that LA-fermented cereals, fruits, vegetables, legumes, and seaweeds are good sources of health-promoting molecules. The obtained products offer a good alternative for a growing number of vegans, vegetarians, and flexitarians, who look for the plant-based, healthy alternatives. However, still more clinical trials evaluating the effect of their consumption on the human health are in demand.

\section{LACTIC ACID FERMENTATION - OVERVIEW}

Fermentation was a common method of food preservation since ancient times. The seasonal production of crops forced the processing of products to make food available throughout the year. Fermentation allows extending the shelf-life of the product, decreases its volume facilitating transportation, and destroys undesirable components. Now, except for extending the shelf-life of food and improving its palatability, the popularity of the fermented food increased because of their nutritional quality and health benefits. And although the role of microorganisms had not been discovered yet, the development of microbiological knowledge and the need for providing larger quantities of food led to understand the potential of fermentation. Recently, selected microbes have been isolated from fermented food matrices for the production of probiotics, considered beneficial for human health [Marco et al., 2017].

There is a wide range of materials, techniques and microorganisms used for fermentation. The fermentation can occur spontaneously or be triggered by the addition of specially selected starter cultures. During this metabolic process, carbohydrates are oxidized in the absence of an electron acceptor. There are only four main fermentation types: alcoholic (for wine and beer production, predominantly by yeast), acetic acid (for vinegar, ascorbic acid and cellulose production), alkaline (for the production of typical Asian and African products, such as dawadawa, ugba, bikalga, kinema, natto, and thuanao), and lactic acid (LA). In this review, the emphasis is put on the last-mentioned type. LA fermentation, as its name suggests, is carried out by lactic acid bacteria (LAB). LAB are Gram-positive, acid-tolerant, in general non-sporulating, catalase-negative bacteria which produce LA as the main product of their fermentation. For many years, LAB have been further divided into homofermentative and heterofermentative ones, which were used to impart the desired features of the fermented products. In the aforementioned classification, the homofermentative LAB include several genera, such as Lactococcus, Pediococcus, Streptococcus, and Enterococcus, which are able to convert glucose to LA with a more than $80 \%$ theoretical efficiency rate [Blajman et al., 2020]. In turn, the heterofermentative bacteria, including the following genera Leuconostoc, Oenococcus, and some of Lactobacillus, e.g. Lactobacillus brevis and Lactobacillus fermentum, except glucose produce significant quantities of ethanol, $\mathrm{CO}_{2}$, and other acids [Moon et al., 2018]. Some LAB, like Lactobacillus plantarum and Lactobacillus pentosus, were classified as facultatively heterofermentative, depending on the environment [Zaunmüller et al., 2006].

\footnotetext{
* Corresponding Author:

E-mail: n.drabinska@pan.olsztyn.pl
} 
Nevertheless, a new taxonomic cassification was introduced in 2020 under which 23 novel genera and a union of Lactobacillaceae and Leuconostocaceae were suggested [Zheng et al., 2020]. In this work, the new reclassification of the genus Lactobacillus was proposed based on the whole genome sequencing of Lactobacillaceae and Leuconostocaceae. The genus Lactobacillus was divided into 25 genera including the emended genus Lactobacillus, which includes host-adapted organisms that have been referred to as the Lactobacillus delbrueckii group, Paralactobacillus, and 23 novel genera named Holzapfelia, Amylolactobacillus, Bombilactobacillus, Companilactobacillus, Lapidi lactobacillus, Agrilactobacillus, Schleiferilactobacillus, Loigolactobacilus, Lacticaseibacillus, Latilactobacillus, Dellaglioa, Liquorilactobacillus, Ligilactobacillus, Lactiplantibacillus, Furfuri lactobacillus, Paucilactobacillus, Limosilactobacillus, Fructilactobacillus, Acetilactobacillus, Apilactobacillus, Levilactobacillus, Secundilactobacillus, and Lentilactobacillus. And despite the fact that in this review the taxonomic names of bacteria are as reffered by the original authors, we decided that the new classification is worth mentioning, because, for example, three groups: Lactobacillus delbrueckii, Lactobacillus casei, and Lactobacillus salivarius, now belong to the most diverse groups even though they had previously been included into the same homofermentative group of LAB.

Regardless of the used taxonomy, the ability of bacteria to produce lactic acid was superior from a technological point of view, and the diversity of the LAB during fermentation depends on the starter culture and can change during the fermentation process, affecting the properties of fermented foodstuff [Moon et al., 2018]. Due to a high enzymatic activity, LAB are able to decompose and detoxify many compounds present in various types of raw materials (e.g., phenolic compounds, colourants, mycotoxins, acrylamide, pesticides) thanks to their high biogenic activity, they also produce many substances with various biological activities (e.g., volatile fatty acids, exopolysaccharides, proteins). All these functions are briefly presented in Figure 1. Such a high biological activity of $\mathrm{LAB}$ and their adaptation abilities are, on the one hand, beneficial and, on the other hand, a risky phenomenon. $\mathrm{LAB}$ are able, inter alia, to receive plasmids carrying antibiotic resistance genes, they can also produce various types of proteins with activities that have not been fully described so far. In a hypersensitive organism, some of these proteins may be immunoreactive. Bacteria are also able to synthesize biogenic amines, the accumulation of which is a disadvantageous effect. The adverse effects of LAB activity are summarized in Figure 2. The current knowledge describing both types of phenomena will be described in detail in this paper.

Plant-based fermented food products are of special interest since they are proposed as a non-dairy alternative for a natural, probiotic administration [Martins et al., 2013]. The advantage of plant-based fermented foodstuff is that they are suitable for vegan and milk- and lactose-intolerant individuals as well as, beside the probiotic microorganisms, contain a wide variety of phytochemicals, minerals, and fibre [Gupta \& Abu-Ghannam, 2012].

In this review, the existing knowledge about the effects of LA fermentation of different types of plant-based food matrices on their health-promoting potential and nutritional quality is presented and discussed based on the most recent studies. Moreover, the toxicological and unfavorable effects are addressed. Finally, the future studies needed to expand the potential of LA fermentation of plant-based food are underlined.

\section{VEGETABLES AND FRUITS}

Fruits and vegetables are sources of carbohydrates, dietary fibre, vitamins, minerals, and phytochemicals, including phenolics, carotenoids, betalains, glucosinolates and many

\section{Benefits}

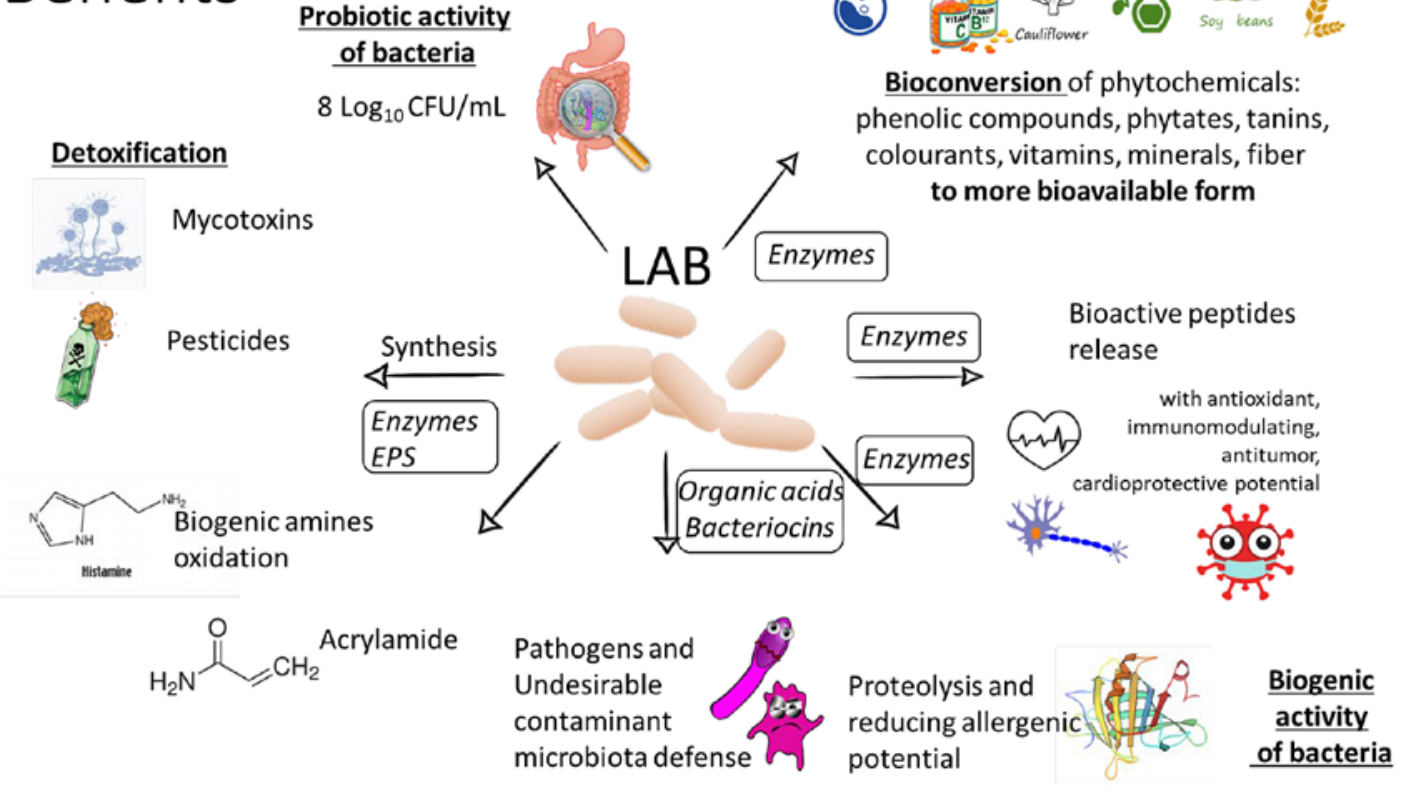

FIGURE 1. The summary of benefits caused by fermentation with lactic acid bacteria (LAB). 
others; therefore, their consumption is highly recommended to maintain good health. To preserve the shelf-life of fruits and vegetables, fermentation was traditionally used worldwide, especially in Asia, Africa, and Eastern Europe. Examples of fermented vegetables include sauerkraut - fermented white cabbage in Eastern Europe, kimchi - Korean dish made of napa cabbage and Korean radish, gundruk - a dish made of fermented green leaves in Nepal, fermented cucumbers, beetroots, tomatoes, and many others including non-alcoholic beverages, summarized and technologically characterized in other reviews [Di Cagno et al., 2013; Garcia et al., 2020]. Fermented products can be manufactured using the LAB starter culture or via the spontaneous fermentation with natural microbiota, which is more frequent in traditional, homemade food products. The spontaneous LA fermentation of raw fruits and vegetables occurs under favourable conditions, such as anaerobiosis, and appropriate salt concentration, water activity, and temperature. LA fermentation results in the physicochemical changes of raw materials due to lower $\mathrm{pH}$ and microbial enzymatic activity. Therefore, fermented products have different nutritional characteristics and profile of bioactive compounds compared to fresh fruits and vegetables. Changes in the nutritional composition and the profile of phytochemicals are highly dependent on the matrix, the LAB strain, and the fermentation conditions.

\section{Safety}

Due to the contact with soil, and during the whole processing and transportation chain, fruits and vegetables can be contaminated with harmful viruses and faecal or coagulase-positive bacteria (Figure 2). Fortunately, these contaminations do not contribute to the foodborne outbreaks since the density of bacteria is too low and the microbial competition with positive microbiota occurs [Di Cagno et al., 2013]. However, in the highly contaminated areas and during inappropriate handling of fruit and vegetable outbreaks are likely. There have been many pathogens reported, however, the most frequent ones include Salmonella sp. in leafy vegetables and Escherichia coli in sprouted seeds and green vegetables [Da Silva Felício et al., 2015; Uyttendaele et al., 2015]. LA fermentation can be applied to reduce the risk of foodborne poisonings and health problems. Usually, the growth of Gram-negative bacteria is inhibited already at the beginning of fermentation [Di Cagno et al., 2013]. However, a recent study has shown that in the carrot juice spiked with foodborne pathogens, including Listeria monocytogenes, Salmonella enterica subsp. enterica Typhimurium, and Escherichia coli $\mathrm{O} 157: \mathrm{H} 7$, the count of bacteria in the initial phase of fermentation increased [Van Beeck et al., 2020]. Fermentation for 8 days at $20^{\circ} \mathrm{C}$ resulted in the drop of the bacterial count below the detection limit, making the fermented juice safe to drink. Moreover, LAB-fermented products, like cider obtained from the fermentation of apple juice, have a high content of acids, resulting in $\mathrm{pH}$ decrease, which prevents the growth of patogenic bacteria [Guiné et al., 2021]. Contrary, the study with cauliflower subjected to the spontaneous fermentation and spiked with Listeria monocytogenes and Salmonella typhimurium showed that LAB were not able to compete with pathogenic bacteria present in the cauliflower until the end of fermentation [Paramithiotis et al., 2012]. This study underlines the need for safety reassessment of spontaneously fermented vegetables and suggests that the application of starter cultures can be a safer option. A recent study has demonstrated the potential of virulent phages infecting mesophilic aerobic bacteria producing nitrite to inhibit the growth of unwanted bacteria [Zheng et al., 2020]. The authors reported that the use of PhageMIX together with Lactobacillus plantarum M6 decreased the count of Pseudomonas mendocina and Enterobacter cloacae below the limit of detection after $48 \mathrm{~h}$ of fermentation in the cucumber juice

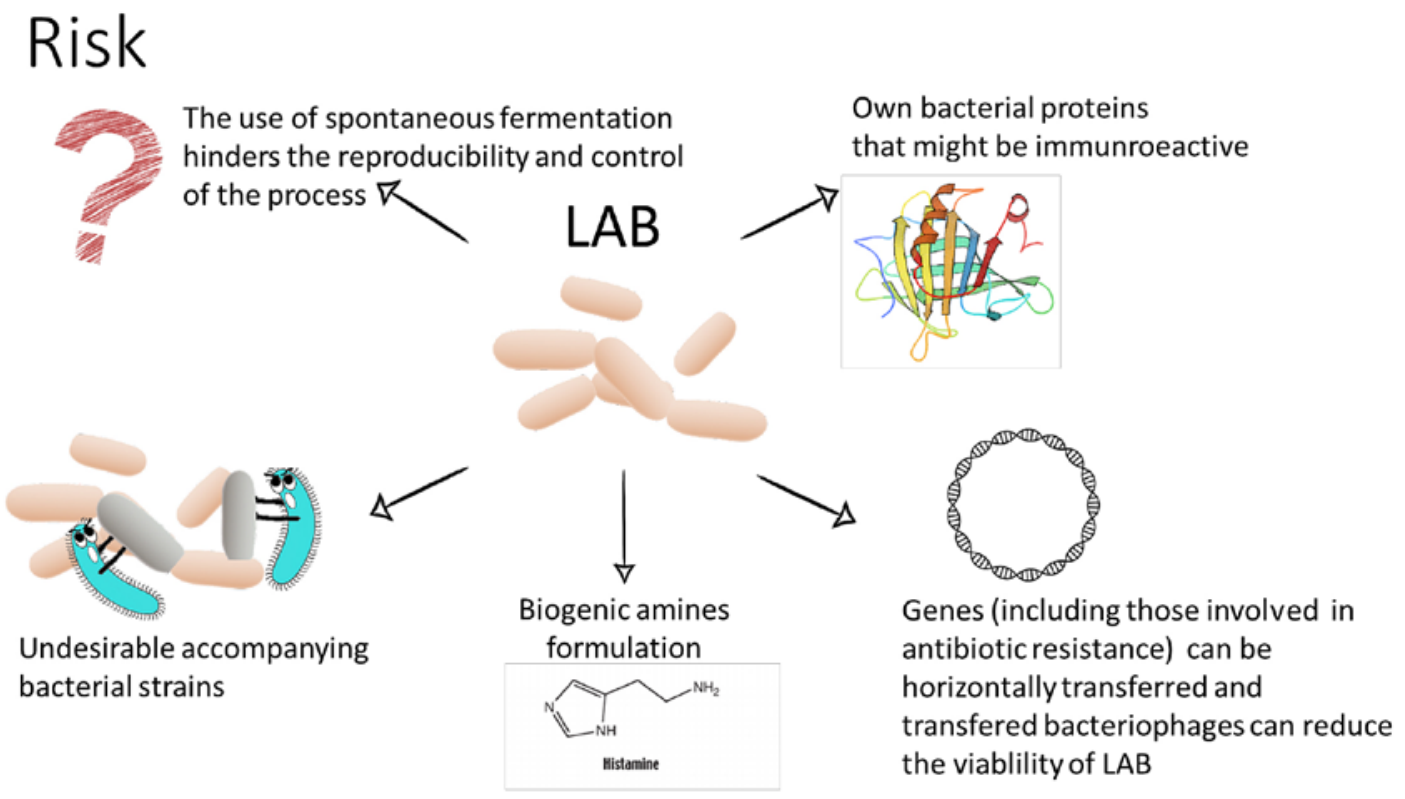

FIGURE 2. The summary of risks associated with fermentation by lactic acid bacteria (LAB). 
artificially contaminated with mesophilic aerobic bacteria. This study suggests that the application of phages can not only improve safety but also reduce the spoilage and losses of fermented food products.

Another risk posed by fermented vegetable consumption is the formation of biogenic amines (BAs), which can be toxic to humans in high concentration. BAs are formed by the decarboxylation of free amino acids by LAB, with the quantities dependent on the bacteria strain [Garai et al., 2007]. Again, the most severe risk is in the homemade products fermented spontaneously, when the unpredictable concentration of biogenic amines can be produced. The study of Alan et al. [2018] showed that putrescine, cadaverine, and histamine were detected in almost all analysed samples of naturally fermented pickled cucumbers with a very wide range of concentrations varying between the samples. Histamine, tyramine, and putrescine are the major BAs in commercially available ciders; however, also high concentrations of cadaverine can be detected as well [Ladero et al., 2011]. The study using qPCR for the quantitative detection of BA producers showed that many bacteria belonging to $\mathrm{LAB}$ are responsible for the high $\mathrm{BA}$ content [Ladero et al., 2011].

\section{Carbohydrates and organic acids}

LAB fermentation and acidification cause changes in the profiles of carbohydrates and organic acids. In the apple, orange, and grape juices which were processed with freeze-dried Lactobacillus plantarum 49, Lactobacillus brevis 59, Lactobacillus paracasei 108, Lactobacillus fermentum 111, and Lactobacillus pentosus 129 strains, the contents of organic acids and sugars varied during storage, depending on the strain added and juice type [Garcia et al., 2018]. Lactobacillus paracasei and Lactobacillus plantarum were able to degrade glucose, malic, tartaric, and citric acids when these acids were available in the matrix, leading to an increase in the content of LA and succinic acid. A recent study has shown that fermentation of elderberry juice with twelve LAB strains resulted in the high LA production [Cirlini et al., 2020]. Glucose and fructose contents did not change during LA fermentation, while malic and citric acids were extensively metabolised, suggesting a switch in the microbial metabolism with the use of organic acids instead of sugars. The fermentation of chokeberry with LAB led to a significant reduction in the total sugar and fructose contents, while in sea buckthorn the content of sugars was not affected, which resulted in a change in the sugar/acid ratio between the fruits [Markkinen et al., 2019]. This suggested that the effect of the fermentation on sugar profile was dependent on the matrix used for fermentation.

\section{Glucosinolates}

Cruciferous vegetables are commonly fermented in many countries with popular products like sauerkraut, kimchi, fermented cauliflowers, etc. These vegetables, apart from the unique flavour and taste are a source of the special group of bioactive compounds - glucosinolates. Glucosinolates and their breakdown products are considered as chemopreventive, reducing the risk of cancer development [Quirante-Moya et al., 2020]. The enzymatic hydrolysis of glucosinolates occurs during the damage of plant tissues (cutting, shredding, chewing), but also through microbial activity. During cabbage fermentation, complete degradation of glucosinolates was observed in the majority of studies [Martinez-Villaluenga et al., 2009; Palani et al., 2016]. Surprisingly, a recent study has shown that the LAB-induced fermentation increased glucosinolate content in the autoclaved broccoli puree [Ye et al., 2019]. However, the authors explained it by improved extractability of glucosinolates from cell walls due to the enzymatic activity of LAB, especially that the content of glucosinolates in the raw material was very low. Glucosinolates are usually hydrolysed to isothiocyanates and nitriles, which are directly responsible for the bioactive potential. Fermentation leads to the formation of isothiocyanates and nitriles; however, the direction of hydrolysis is strain-dependent. Mullaney et al. [2013] showed that LAB hydrolysed glucosinolates mainly to nitriles, while Enterobacteriaceae hydrolysed them mostly to isothiocyanates. The opposite effect was reported by Cai et al. [2019], who observed an increase in sulforaphane, an isothiocyanate derived from glucoraphanine, in LAB-fermented broccoli puree. Sulforaphane, which is considered as one of the strongest anticancer isothiocyanates [Soundararajan \& Kim, 2018], was found stable in fermented broccoli puree even up to four months of storage at $4^{\circ} \mathrm{C}$ [Cai et al., 2019]. The differences in the results obtained by various authors can be related to the stage of fermentation. The profile of glucosinolate breakdown products depends on fermentation conditions and the profile of glucosinolates in the raw material. In sauerkraut, the major breakdown products were ascrobigen and allyl isothiocyanate derived from glucobrassicin and sinigrin, respectively, i.e. two main glucosinolates in cabbage [Ciska et al., 2009; Palani et al., 2016], while in broccoli products, the major breakdown product was sulforaphane derived from the dominant glucoraphanine [Cai et al., 2019]. Nevertheless, it needs to be emphasised that glucosinolates and their breakdown products easily leach into water [Ciska et al., 2016]; therefore, the brine from fermentation can also be used as a source of bioactive compounds, with the confirmed health-promoting activity [Hallmann et al., 2017].

\section{Carotenoids}

Another important group of compounds are colourants, widely distributed in fruits and vegetables. Carotenoids are tetraterpenoids, imparting plants yellow, orange, and red colour. Besides being pigments, some of them are precursors of vitamins ( $\beta$-carotene, the precursor of vitamin $A$ ) and they are strong antioxidants, thus confer several health benefits [Meléndez-Martínez, 2019]. LA fermentation can affect their content in plants. In a study of Oloo et al. [2014], different varieties of orange-fleshed sweet potatoes were fermented with Lactobacillus plantarum MTCC to measure the retention of $\beta$-carotene. Its initial content differed between the potato varieties from 0.031 to $17.02 \mathrm{mg} / 100 \mathrm{~g}$. However, irrespectively of its initial content, the retention of $\beta$-carotene reached up to $93.97 \%$, indicating LA fermentation to prove well in carotein preservation [Oloo et al., 2014]. In another study, LA fermentation was applied as a preservation method for a tomato puree, and the fate of lycopene and $\beta$-carotene was evaluated [Bartkiene et al., 2013]. Tomato pulp was fermented 
with LAB, including Lactobacillus sakei KTU05-6, Pediococcus acidilactici KTU05-7, and Pediococcus pentosaceus KTU05-8, capable of producing bacteriocins. LA fermentation with Pediococcus pentosaceus and Lactobacillus sakei resulted in an apparent increase in lycopene content in some of the tomato varieties, causing a higher cis/trans lycopene ratio in fermented tomato, thereby increasing the bioavailability of these compounds in the human body [Unlu et al., 2007]. However, although the content of the carotenoids increased after fermentation, it does not mean that their degradation did not occur. The increase in carotenoid content was supposedly due to the enzymatic degradation of cell walls and better extractability, and not to de novo synthesis of carotenoids [Unlu et al., 2007]. From 15 to $45 \%$ degradation of $\alpha$-carotene and $\beta$-carotene was noted in the carrot juice fermented for $24 \mathrm{~h}$ with Bifidobacterium strains (Bifidobacterium lactis Bb-12, Bifidobacterium bifidum B7.1 and B3.2) [Kun et al., 2008]. The degradation of carotenoids was also indirectly presented in the work of Lee et al. [2018], who analysed volatile organic compounds in red pepper fermented with Lactobacillus parabuchneri. These authors reported an increase in the contents of some degradation compounds derived from carotenoids, including $\beta$-ionone, $\beta$-cyclocitral, $\alpha$-ionone, and $\beta$-damascenone after LA fermentation. $\beta$-Damascenone, a potential breakdown product of neoxanthin, was not detected in the raw red pepper and its content increased successively during fermentation, suggesting that the degradation of carotenoids did occur. While in a recent study, $120 \mathrm{~h}$ of acerola and guava fruit by-product fermentation by strains of Lactobacillus sp. had no effect on the total carotenoid content [de Oliveira et al., 2020]. In general, the impact of LA fermentation on the content of carotenoids seems to depend on the chemical structure, fermented matrix, and fermentation conditions.

\section{Betalains}

Another group of plant pigments is represented by betalains, water-soluble nitrogen-containing compounds, which can be further divided into red-violet betacyanins and yellow-orange betaxanthins. Betalains are not widely present in the plant world and are detected mainly in plants of the order Caryophyllales. Their main source among vegetables is a beetroot. Czyżowska et al. [2006] evaluated the effect of LA fermentation with six LAB strains on the stability of betalains in beetroot juice made of two beetroot varieties. They reported the presence of five betalains including four betacyanins: betanin, isobetanin, betanidin, isobetanidin, and neobetanin; and one betaxantin, i.e., vulgaxanthin I. Interestingly, betanidin and isopetanidin were detected only in the fermented products. Two beetroot varieties and juices made of them differed in the betalain profiles. The Chrobry variety had a higher content of betanidin than betalain, while in Czerwona Kula variety, this ratio was reversed [Czyżowska et al., 2006]. The stability of the betalains in the fermented beetroot juice was evaluated in another study of these authors [Klewicka \& Czyżowska, 2011]. Beetroot juice was fermented by Lactobacillus brevis 0944 and Lactobacillus paracasei 0920, stored for 180 days at $4^{\circ} \mathrm{C}$, and determined for betalain content. Initially, betalains were relatively stable and after
7 days of LA fermentation, their content decreased by $12 \%$ and remained at the same level up to 30 days of fermentation. Drastic drops were observed after 90 and 180 days of fermentation, reaching only 32 and $25 \%$ of the initial betalain content. Similarly, the storage of LA-fermented, grated beetroot for seven months resulted in about three-fold decrease in betalain content [Czyżowska et al., 2020]. The content of betalains seems to depend on the form of product made from a vegetable. In a recent study, fresh, dried, and freeze-dried beetroot products sprayed with $\mathrm{LAB}$ were compared in terms of betalain content [Barbu et al., 2020]. Freeze-dried beetroot had seven-times more betalains than the control, unprocessed beetroot and other fermented beetroot products. Moreover, the ratio between betacyanin and betaxanthin differed between the food products, with betaxanthins prevailing in freeze-dried beetroot, betacyanins in fresh, control beetroot, and the equal ratio between both betalains in fresh LAB-processed beetroot and dried product [Barbu et al., 2020]. Importantly, fermented beetroot has a lower content of betanin compared to the fresh, boiled, jam-processed, and juice beetroot [Guldiken et al., 2016]. The level of isobetanin in the pickled beetroot was also lower than in the majority of the analysed beetroot products.

Next to beetroot, betalains can be found in other plants, which are however rarely subjected to LAB fermentation. The latest study has shown the effect of LA fermentation of Opuntia ficus-indica (prickly pear) juice by Weissella cibaria and Pediococcus pentosaceus on the content of bioactive compounds [Allendez et al., 2020]. The authors reported that the total phenolic and betalain contents were preserved after LA fermentation, thus exhibiting antioxidant potential. The study with fresh fruits of prickly pear fermented by Leuconostoc mesenteroides showed that the content of betalains was rather stable [Di Cagno et al., 2016]. After 21 days of fermentation, the content of betaxantins decreased slightly and the content of betacyanins was higher than in the control, unprocessed fruit. However, the differences in the betalain content were noticeable between the fruits fermented with different LAB strains. The highest content of both betaxantines and betacyanines was noted in prickly pear fermented with Leuconostoc mesenteroides OP23, while the lowest value was noted for that fermented with Leuconostoc mesenteroides OP4 [Di Cagno et al., 2016].

\section{Phenolic compounds}

Phenolic compounds are one of the most abundant classes of plant secondary metabolites, widely distributed in fruits and vegetables. They are associated with a high antioxidant activity, therefore are implicated in lowering the risk of diseases caused by oxidative stress, like cancer, cardiovascular and neurodegenerative disorders [Vauzour et al., 2010]. The effect of LA fermentation on the content of phenolic compounds and antioxidant capacity in fruits and vegetables has been extensively investigated. In general, with a very broad range of studies on the antioxidant activity and polyphenol content in LAB-fermented fruits and vegetables, no predictable trend of changes could be obtained. The discrepancies are associated with analysing different plants using different starter cultures versus spontaneous fermentation, different 
conditions of the process, and also different assays used for the antioxidant capacity measurement. The only conclusion repeated in many works is that the controlled fermentation with fully-defined starter cultures is more beneficial than the spontaneous fermentation [Pistarino et al., 2013; Yang et al., 2014].

The content of phenolics and antioxidant capacity were determined in LA-fermented fruits including orange, pomegranate, cherry, mulberry, elderberry, cherimoya, kiwi, and many others, mainly in the form of juice [Chen et al., 2019; de la Fuente et al., 2021; Filannino et al., 2013, 2015; Isas et al., 2020; Kwaw et al., 2018; Ricci et al., 2019; Zhou et al., 2020]. The study of Filannino et al. [2013] evaluated the effect of LA fermentation on the organoleptic and nutraceutical potential of pomegranate juice. The total content of phenolics decreased during fermentation as compared to the baseline, however, remained stable and higher than in the pomegranate juice which was fermented without the starter culture. Differences were also observed between the effects of the individual LAB strains on the total phenolic content. The highest phenolic content was determined in juice fermented with Lactobacillus plantarum C2. A similar trend was observed for the antioxidant capacity determined by an assay using 2,2-diphenyl-1-picrylhydrazyl radical (DPPH*). The content of ellagic acid increased significantly in all LAB-fermented juices, however again, the highest content was determined in the juices fermented with Lactobacillus plantarum C2 [Filannino et al., 2013]. An attempt to understand the metabolism of protocatechuic, caffeic, and p-coumaric acids by phenolic acid decarboxylases and reductases of Lactobacillus strains in a strain-specific manner was undertaken in cherry juice and broccoli puree [Filannino et al., 2015]. The majority of Lactobacillus strains exhibited the ability to decarboxylate protocatechuic acid to catechol, while strains of Lactobacillus plantarum and Lactobacillus spicheri Lp38 decarboxylated caffeic acid to vinyl catechol. However, other strain of LAB metabolised the same acid in a different way. Lactobacillus fermentum FUA3165 reduced caffeic acid to dihydrocaffeic acid, while $p$-coumaric acid was metabolised to $p$-vinylphenol and phloretic acid by the majority of Lactobacillus plantarum and Lactobacillus fermentum strains [Filannino et al., 2015]. In another study, Lactobacillus plantarum was used to ferment kiwifruit pulp, and the changes in the antioxidant potential and the profile of phenolic compounds were detected [Zhou et al., 2020]. The fermentation led to an increase in the content of total phenolics, flavonoids as well as 6,7-dihydroxycoumarin, $p$-coumaric acid, and protocatechuic acid in kiwi product. The major phenolic acids were protocatechuic and chlorogenic acids, while gallic acid, chlorogenic acid, (-)-epicatechin, and (+)-catechin were degraded during LA fermentation. The increase in the polyphenolic compounds enhanced the antioxidant capacity measured using DPPH and 2,2'-azino-bis(3-ethylbenzthiazoline-6-sulfonic acid) diammonium salt (ABTS) assays [Zhou et al., 2020]. An innovative beverage based on orange juice and milk fermented with Lactobacillus brevis POM and Lactobacillus plantarum (TR-7, TR-71, TR-14) was proposed by de la Fuente et al. [2021]. All the strains used led to an increase in the antioxidant capacity; however, the effect on the content of phenolic compounds was more strain-dependent. The greatest amount of phenolic compounds was determined in the beverage fermented with Lactobacillus plantarum TR-71 and TR-14 for $72 \mathrm{~h}$. Moreover, the production of compounds participating in food preservation, such as DL-3-phenyllactic acid and 3,4-dihydroxyhydrocinnamic acid, was detected in the LAB-fermented beverage [de la Fuente et al., 2021].

Moreover, a wide variety of vegetables has been fermented and the fate of phenolics and antioxidant capacity caused by these compounds in these products was evaluated. Spontaneously fermented asparagus was reported to have a ferric ion reducing antioxidant power (FRAP); however, LA fermentation did not affect $\mathrm{DPPH}{ }^{*}$ and $\mathrm{ABTS}^{\circ}{ }^{+}$scavenging activities as well as total phenolic and flavonoid contents [Tabaszewska et al., 2018]. On the other hand, fermentation caused the reduction in contents of individual phenolic compounds, total sugars, and B vitamins. Broccoli purre fermented with seven strains of broccoli-derived LAB was used to track the biotransformation of polyphenolic compounds [Ye et al., 2019]. The authors reported the presence of ten phenolic compounds, which total content increased significantly after LA fermentation. In the broccoli purre fermented with Lactobacillus plantarum, the highest increase in phloretic acid was determined compared to that fermented with other LAB strains. Therefore, the authors suggested that LA fermentation could be a promising tool to increase the health-promoting potential of vegetables. Another factor that can affect bioactive compounds might be the conditions of storage. A study of Kapusta-Duch et al. [2017] compared the effect of four-month sauerkraut storage in low-density polyethylene bags (PE-LD) and metalised polyethylene terephthalate foil (PET met/PE) on the content of ascorbic acid, total phenolic content, and antioxidant activity. The ascorbic acid and total phenolic contents decreased during four-month storage; however, there was no difference between container types. Nevertheless, the type of container affected the antioxidant capacity of sauerkraut. The product kept in PET met/PE bag had a higher antioxidant capacity than the cabbage kept in PE-LD bag and the non-stored sauerkraut.

A special group of phenolics are anthocyanins, responsible, similarly to betalain, for the red-purple colour of fruits and vegetables. Red cabbage was found to be a source of twenty different non-acylated and acylated anthocyanins with the dominant cyanidin 3-diglucoside 5-glucoside [Wiczkowski et al., 2015]. The spontaneously fermented red cabbage was found to have a lower by $24 \%$ content of anthocyanins than the fresh cabbage; however, the loss of these compounds was lower than in stewed cabbage. Interestingly, fermentation reduced the bioavailability of anthocyanins from red cabbage, thus increasing the intestinal capacity measured in the plasma of subjects consuming a fermented product [Wiczkowski et al., 2016]. Shalgam, a traditional Turkish LA-fermented beverage made of black carrot, was found to be a source of bioactive compounds, including anthocyanins responsible for the colour of the drink [Toktas et al., 2018]. During the initial stage of fermentation, the content of bioactive compounds was lower than in the raw red carrot and the final shalgam. Interestingly, even though sixteen polyphenolic compounds were detected in the beverage, only five phenolics were detected in bioavailability test [Toktaş et al., 2018]. 


\section{Pro- and prebiotic activity}

An important feature of fermented fruits and vegetables is their effect on the human gut. Fermented plant-based products can be a substitute to dairy probiotics, satisfying needs of vegans and individuals suffering from allergies. The effect of fermentation conditions on the survival of the probiotics in pomegranate juice has recently been reported [Mustafa et al., 2019]. The authors found that fermentation of Lactobacillus casei at $37^{\circ} \mathrm{C}$ without agitation resulted in the highest biomass density. Another alternative to dairy probiotics can be modified kombucha, which originally is a fermented tea beverage, prepared by fermenting sweetened black tea with tea fungus, yeasts, and acetic acid bacteria. A study of Cvetković et al. [2019] showed the potential of wild strains of LAB in kombucha preparation, without affecting the activity of tea fungus, thus forming grounds for the development of a new, probiotic beverage. Furthermore, fermented fruits can also be a source of prebiotics. The prebiotic activity of polysaccharides from LAB-fermented longan pulp was evaluated in a study of Huang et al. [2019]. These authors reported that logan pulp fermented for $12 \mathrm{~h}$ exhibited a stronger stimulatory effect on Lactobacillus strain proliferation, proving the prebiotic activity of the LAB-fermented product.

Fermented products have been reported to influence health parameters evaluated in animal and humans studies. Cactus pear juice fermented with autochthonous Lactobacillus plantarum S-811 was found to decrease body weight and to normalise insulin resistance, hyperglycemia, and hyperlipemia parameters in obese mice [Verón et al., 2019]. Moreover, the intake of asparagus polysaccharides fermented with Lactobacillus plantarum NCU116 was effective in alleviating cyclophosphamide-induced hepatotoxicity in mice [Zhang et al., 2020]. The fermented product reduced the level of hepatic biochemical markers (alanine aminotransferase, aspartate aminotransferase, alkaline phosphatase, and lactic dehydrogenase), and proinflammatory cytokines (tumour necrosis factor- $\alpha$ and interleukin-1 $\beta$ ). Moreover, the fermented asparagus polysaccharides affected the metabolism of bile acids and shortchain fatty acids as well as glutathione homeostasis [Zhang et al., 2020]. A very interesting study was reported by Zhou et al. [2019]. They performed in vitro assays proving that persimmon juice fermented with co-culture of Lactobacillus plantarum $\mathrm{C} 17$ and Lactobacillus pentosus Lp-B exhibited antihangover and antihypertensive activity. The selected strains of bacteria were capable of synthesising $\gamma$-aminobutyric acid (GABA), which was suggested to be responsible for antihangover capacity evaluated by alcohol dehydrogenase activation rate, acetaldehyde dehydrogenase activity, and hydroxyl inhibition rate. All these studies showed that the consumption of fermented fruits, vegetables, and beverages can confer a very broad range of beneficial effects on human health.

\section{CEREALS AND PSEUDOCEREALS}

The staple human food all over the world consists of carbohydrate-rich products. It is estimated that approx. $60 \%$ of the calorie intake is derived from the three main kinds of cereals: wheat, maize, and rice [Hermann, 2009]. And despite the great importance of the cereal-based products, their nutritional quality is not always sufficient, since they have a lower protein content than other food matrices, like meat and dairy, are deficient in essential amino acids, like lysine, and can contain undesired compounds, such as amylase/ trypsin inhibitors (ATIs), phytates, and others summarised in a recent, excellent review [Samtiya et al., 2020]. Moreover, the palatability of unprocessed cereals can be unsatisfactory. Fermentation of the cereals results in the reduction of the content of carbohydrates and non-digestible poly- and oligosaccharides [Albiac et al., 2020]. Moreover, the deficiency of amino acids can be alleviated through their synthesis by bacteria responsible for fermentation [Omoba \& Isah, 2018]. The application of LA fermentation in the processing of starch-containing materials enables the formulation of several products, such as bread, noodles, pastries, confectionery, and beverages with typical sour-sweet taste and butterish aroma, thus reducing the need for flavourings and additives. Importantly, products obtained by fermentation with LAB confer additional health benefits related to the probiotic characteristics of many LAB alone [Bartkiene et al., 2019] and their ability to synthesise vitamins, amino acids, and short-chain fatty acids, considered as postbiotics.

$\mathrm{LAB}$ are commonly used as a starter culture for sourdough in breadmaking [Yagmur et al., 2016]. It is estimated that there are about 50 different species of LAB being a part of the sourdough microbiota. They differ around the world, but the most common ones include Leuconostoc, Lactobacillus, Streptococcus, Pediococcus, Micrococcus, and Bacillus, regardless of the flour type [Minervini et al., 2014]. LAB in the sourdough originate mainly from the flour used for breadmaking, but also from other ingredients and the production environment. The bread made with the sourdough features a better quality as compared to the bread processed only with Baker's yeast, which is more often used in the food industry for breadmaking. Sourdough-based bread has longer shelf-life and more pleasant sensory attributes. And, despite the large scale production of bread which should be quick and efficient, the consumer demand for more nutritious, natural, and healthy food forced the baking industry to go back to the traditions and to produce the sourdough-based products. Only in Italy, there are recognised more than 200 sourdough types, of which many are unique enough to be considered as protected geographical indication (PGI) or protected designation of origin (PDO) [Palla et al., 2017].

\section{Safety}

LAB not only modify the flavour and taste of the bread but also improve its safety. In the course of fermentation, the presence of undesired components, such as ATI, can be reduced, mitigating the immune response to the grain-based products [Huang et al., 2020]. The phytates can be significantly reduced after fermentation [Kheterpaul \& Chauhan, 1991; Liang et al., 2008], improving the availability of minerals, including zinc, iron, and calcium. Furthermore, fermentation was found to be effective in detoxifying cereals, reducing the aflatoxin level in the maize-based product [Wacoo et al., 2019].

Bread may also contain acrylamide, a harmful and potential cancerogenic compound formed during the heat treatment via the Maillard reaction. Therefore, there have been attempts 
to reduce its level in food. Nachi et al. [2018] showed that wheat bread obtained from sourdough inoculated with Lactobacillus brevis, Lactobacillus plantarum, Pediococcus pentoseus, and Pediococcus acidilactici had a lower acrylamide content than the bread prepared only with yeast. Similar findings were later confirmed in a study where the rye-wheat bread with LAB sourdough was compared to the bread acidified with LA, and the authors found that Lactobacillus plantarum sourdough decreased the acrylamide content in the bread, while the application of the acid itself did not show any effect on the bread quality [Bartkiene et al., 2017]. The acrylamidereducing activity is suggested to be strain-dependent, and not every LAB can have a similar effect. In the study comparing the effectiveness of sourdough with four strains of Lactobacillus, Lactobacillus rhamnosus was found to be the most efficient in decreasing the acrylamide content in whole-wheat bread [Esfahani et al., 2017].

Another benefit of the LAB sourdough affecting the safety of cereal-based products is its ability to reduce toxins. Malting grains are often contaminated with Fusarium sp. and their mycotoxins [Habler et al., 2016]. The application of several LAB strains, such as Lactobacillus sakei KTU05-6, Pediococcus acidilactici KTU05-7, and Pediococcus pentosaceus KTU05-8, KTU05-09, and KTU05-10 decreased the content of deoxynivalenol, zearalenone, and toxins T-2 and HT-2 even by $70 \%$ in malting grains. The applied strains, not only reduced the content of the toxins in grains, but also inhibited Fusarium sp. growth [Juodeikiene et al., 2018]. The effectiveness of LA fermentation in reducing Fusarium mycotoxin content was also confirmed in a study with whole grain sorghum [Adebo et al., 2019]. These authors found that strains of Lactobacillus, especially Lactobacillus fermentum FUA 3321, were able to reduce the total content of mycotoxins even by $98 \%$. The identification of strains effective in removing mycotoxins during sourdough fermentation is an important concern of the food industry. A recent study has shown that Lithuanian whole milled and fractionated wheat grains from 2017 and 2018 harvest were highly contaminated with mycotoxins [Zadeike et al., 2021]. The bran and coarse flour had a high content of several mycotoxins, which has to be considered while recommending the whole-grain products. The 48-h fermentation of wheat fractions with LAB led to a significant reduction in the content of mycotoxins; however, the rate of reduction was dependent on the fraction and mycotoxin type. Only enniatin $B_{1}$ was fully removed from the whole meal samples, while other mycotoxins were still detected [Zadeike et al., 2021].

\section{Phenolic compounds}

LA fermentation can also be beneficial to bioactive compounds. Starch-based crops are rich in different phytochemicals, including phenolic compounds. LA fermentation can affect their composition in the product; however, the extent and the direction of the changes depend on grain types, LAB species, and fermentation conditions $(\mathrm{pH}$, temperature, and duration). Single-strain solid-state LA fermentation with Lactobacillus rhamnosus resulted in a lower bound phenolic content in fermented wheat bran compared to that in fermented autoclaved bran [Spaggiari et al., 2020]. In contrast, an increase in total free phenolic content was observed when the fermentation was conducted for 24 or $48 \mathrm{~h}$, suggesting that Lactobacillus rhamnosus was able to metabolise the conjugated phenolic compounds. This phenomenon led to an increase in the antioxidant capacity in the wheat bran assessed using DPPH, FRAP, and ABTS assays. Similarly, an increase in the antioxidant capacity and total phenolic content was observed in maize mashes fermented with a Fresco DVS 1010 culture (Lactococcus lactis ssp. lactis, Lactococcus lactis ssp. cremoris, and Streptococcus thermophilus) [Matejčeková et al., 2019]. Interestingly, the effect of LAB on the profile of phenolic compounds is dependent on the plant matrix. A recent study of Garzón et al. [2020] evaluating the influence of LA fermentation on phenolics in red and white sorghum fermented products, has shown differences in phenolic acid profiles. In the fermented product made of red sorghum, an increase of $p$-coumaric acid content was observed, while the contents of caffeic, ferulic, and sinapic acid decreased. In turn, in the white sorghum-based product, the contents of free $p$-coumaric and bound sinapic acids increased [Garzón et al., 2020]. The authors explained changes in the phenolic acids by the activity of LAB enzymes to hydrolyse the complex forms of phenolics, increasing free forms of phenolic acids. The changes in the contents of phenolic acids are related to the cellular energy balance of LAB, which can use hydroxycinnamic acids as external acceptors of electrons [Filannino et al., 2014]. The metabolism of phenolic compounds by LAB is mediated by several enzymes, including decarboxylases, reductases, glycosidases, and esterases [Esteban-Torres et al., 2015; Santamaría et al., 2018]. The composition of low-molecular weight phenolic compounds in the fermented sorghum-based porridge, typical in Africa and called ting, was found to additionally depend on the tannin content [Adebo et al., 2018]. Fermented high tannin-sorghum had a higher content of (+)-catechin, gallic acid, and quercetin than the ting made of low tannin-sorghum. Interestingly, the single strain fermentation was more beneficial in terms of bioactive compounds than the co-culture of Lactobacillus fermentum strains, and the strain FUA 3321 yielded better properties of ting [Adebo et al., 2018].

LAB-fermented flours and their effect on bioactive compounds in baked products have recently gained much scientific attention. A study comparing spontaneous fermentation of quinoa flour and flour fermented with Lactobacillus plantarum ATCC 8014 showed that the controlled LA fermentation resulted in a higher content of flavonoids, total phenolics, organic acids, and folic acid in muffins [Chiş et al., 2020]. The higher content of phenolics resulted also in a higher antioxidant capacity of the finished product, which can be used to improve the quality of the gluten-free products, known for their poorer health-beneficial properties [Conte et al., 2019]. A recent study with biscuits made of buckwheat flour fermented individually with $14 \mathrm{LAB}$ strains has shown that changes in the total phenolic content in flours were highly dependent on LAB strain [Zieliński et al., 2020]. The highest total phenolic content was determined in the flour fermented with Lactobacillus plantarum IB and in the water biscuits made of this flour. LAB fermentation contributed to the increased contents of $p$-coumaric, sinapic, protocatechuic, and caffeic acids, 
and to decreased contents of vanillic acid in flours. However, the thermal processing during biscuit production decreased the content of the majority of phenolic acids, except the vanillic and protocatechuic ones. The changes in the contents of phenolic compounds, especially $p$-coumaric, sinapic, syringic, vanillic, and protocatechuic acids as well as kaempferol, quercetin, apigenin, and orientin contributed to a decrease in the angiotensin-converting enzyme (ACE) inhibitory activity of the flour, which was much higher in the digested biscuits [Zieliński et al., 2020]. Interestingly, the biscuits with the highest content of phenolics were characterised by the highest hardness [Wronkowska et al., 2018]. The same research group showed that water-biscuits made of buckwheat flour fermented with LAB inhibited formation of advanced glycation end-products (AGEs), which was highly strain-dependent [Zieliński et al., 2020]. Biscuits made of flours fermented with Lactobacillus plantarum W42, Lactobacillus casei $2 \mathrm{~K}$, and Lactobacillus rhamnosus GG had the highest anti-AGEs activity, significantly higher than the control, non-fermented biscuits. However, biscuits made of flours fermented with Lactobacillus delbrucki subsp. bulgaricus 151 and Streptococcus thermophilus MK-10 had a much lower anti-AGEs potential even compared to the control biscuits, confirming again that the effect of LA fermentation on the health properties is highly strain-dependent.

The processing of the cereals and pseudocereals results in the generation of the vast amount of by-products. The by-products of wheat, maize, and rice are rich sources of nutrients and bioactive compounds; therefore, attempts have been made to utilise them as innovative functional foods. One of the methods which can be used to process grain wastes can be LA fermentation. There is a recent comprehensive review summarising the latest attempts of exploiting the potential of the cereal industry by-products [Verni et al., 2019], therefore this aspect will not be described in this review article.

\section{Probiotic activity}

LA-fermented cereal-based products are of great importance from the gut health point of view. Many LAB are considered as probiotics, which are live organisms providing a health benefit to the host when ingested in adequate quantities [Hill et al., 2014]. An important part of this definition is "adequate quantities"; therefore, despite containing LAB classified as probiotics, many fermented products, cannot be considered as probiotic. A value of $6 \log _{10} \mathrm{CFU} / \mathrm{mL}$ based on a daily dose of $100 \mathrm{~mL}$, required for prebiotics, was obtained in LAB-fermented cereal-based beverages made of the mixture of oat, barley, and malt [Salmerón et al., 2015]. After $10 \mathrm{~h}$ of incubation, the count of individual LAB strains was around $8 \log _{10} \mathrm{CFU} / \mathrm{mL}$ in all analysed beverages. However, the applied bacterial strains affected the sensory properties of the beverages, and the product fermented with Lactobacillus plantarum NCIMB 8826 was the most acceptable, which was related to the highest content of acetaldehyde [Salmerón et al., 2015]. The type of cereal significantly affects bacterial growth. Cell count of approx. $8 \log _{10} \mathrm{CFU} / \mathrm{mL}$ could be reached within $6 \mathrm{~h}$ of fermentation of malt, which may be attributed to the presence of considerable amounts of monosaccharides (glucose and fructose) and disaccharides (maltose and sucrose) in the malt medium [Rathore et al., 2012]. The type of bacteria has to be considered while designing a probiotic product. Since there are LAB strains which are homofermentative, like Lactobacillus acidophilus, the main product of their metabolism will be LA formed during the glycolysis of carbohydrates in the Embden-Meyerhof pathway. On the other hand, facultatively heterofermentative bacteria, like Lactobacillus plantarum, produce other acids, like acetic acid, beside the LA in a pentose phosphate pathway. These differences in the LAB metabolism can affect consumer perception of LAB-fermented products, making some of them unacceptable to consumers. In a recent study, strains of Pediococcus spp. isolated from Iranian traditional fermented cereal-dairy product called Tarkhineh showed health beneficial properties [Vasiee et al., 2020]. Three isolated strains were successfully tested against several pathogenic bacteria, like Escherichia coli ATCC 25922, Pseudomonas aeruginosa PTCC 1707, Salmonella typhimurium PTCC 1609, and Staphylococcus aureus ATCC 25923. Moreover, one strain, Pediococcus acidilactici IAH-5, showed exceptional features of cholesterol removal rate, antioxidant capacity, and a high auto-aggregation potential, indicative of probiotic adhesion to the epithelial cells [Vasiee et al., 2020]. Some LAB can also feature amylase activity, increasing the availability of energy from starch-containing sources and improving the energy density of food products [Nguyen et al., 2007]. A recent study has evaluated the amylase activity of 132 LAB strains isolated from Chinese fermented food products [Xu et al., 2020]. Out of these 132 strains, only three strains of Lactobacillus plantarum were found to exhibit the amylase activity and were further characterised to confirm their potential as probiotics. More amylolytic LAB were isolated from the traditional Bulgarian sourdough [Petkova et al., 2020]. The authors reported the presence of $36 \mathrm{LAB}$ with amylase activity confirmed with the presence of six amylolytic genes, and the expression of the $\alpha$-amy gene.

Positive effects of LAB-fermented cereal products were confirmed in animal and human studies. Lactobacillus plantarum DSMZ16627 and Pediococcus acidilactici NCIMB3005-fermented animal feed consisting of a mixture of barley $(45 \%)$, wheat $(42 \%)$, and wheat feed $(12 \%)$ was given to pigs for 55 days to evaluate its effects on pig growth, nutrient digestibility, and pig gut health [Torres-Pitarch et al., 2020]. LA-fermented feed increased total tract nutrient digestibility and average daily body weight gain, as well as reduced contents of caecal butyrate and propionate. Moreover, it caused changes in the intestinal microbiota. The pigs fed with LAB-fermented feed had a lower caecum abundance of taxa negatively associated with pig growth, including Megasphaera, Bifidobacterium, and Streptococcus [Torres-Pitarch et al., 2020]. A single-blinded and parallel clinical trial study where subjects were eating fermented barley-wheat flour noodle for ten weeks showed a lower level of fasting blood glucose, HbAlc, and triglycerides in subjects with the metabolic syndrome [Pan et al., 2020]. Moreover, improved satiety and the reduction of fat mass, without the loss of lean mass, was observed in a group consuming fermented noodles. The above-mentioned studies proved that the LA-fermented cereal-based products could be a good alternative to dairy probiotics. 


\section{Dietary fibre}

Another important factor related to gut health is the intake of dietary fibre. LA fermentation of starch-based products was found to increase the ratio of soluble to insoluble fibre [Mihhalevski et al., 2013]. Interestingly, the measured content of dietary fibre was higher after fermentation than the one calculated from the content of fibre in individual raw materials used for rye bread production. However, in the same study, the LA fermentation resulted in the significant loss of B-complex vitamins, especially thiamine, riboflavin, and pyridoxine, which can be explained by microbial activity [Mihhalevski et al., 2013]. A similar finding regarding dietary fibre was found in a study characterising wheat-naked barley bread after sourdough fermentation with the commercial LV1 starter culture consisting of LAB and yeast [Pejcz et al., 2017]. The bread produced had not only improved technological properties but also higher contents of dietary fibre, arabinoxylans, and $\beta$-glucans. $\beta$-Glucans are $\beta$-D-glucose polysaccharides with mixed $(1 \rightarrow 3),(1 \rightarrow 4)$ linkages consisting of a significant part of barley dietary fibre. They were repeatedly reported to lower serum cholesterol, glucose, and lipid profiles, regulate intestinal microbiota homeostasis, boost the immune system, support body weight maintenance, and even prevent cancer development [Chaichian et al., 2020; De Angelis et al., 2015; El Khoury et al., 2012; Tong et al., 2015]. The activity of $\beta$-glucan itself is also modified by LA fermentation. A recent study has shown that $\beta$-glucan fermented with Lactobacillus plantarum dy-1 had lower molecular weight as a result of degradation by LAB. The structural changes of $\beta$-glucan enhanced its in vitro physiological activities, like the $\alpha$-amylase, $\alpha$-glucosidase, and lipase-inhibitory activity as well as the cholesterol adsorption capacity [Xiao et al., 2020].

\section{Development of free-from products}

With the increasing number of food allergies, gluten-related disorders, and intolerances to individual food components, several attempts have been made to reduce the level of triggering components in cereal-based food. Fermentable oligosaccharides, disaccharides, monosaccharides, and polyols (FODMAPs) are considered to be one of the factors inducing intestinal symptoms in the irritable bowel syndrome (IBS). The content of fructans in grain-based products is too high for the subjects sensitive to FODMAP, and LA fermentation was found to decrease it. Rye bread made with sourdough produced with Lactobacillus plantarum was found to have a much lower fructan content without compromising technological properties and consumer acceptance [Pejcz et al., 2020]. However, the optimisation of the fermentation conditions is crucial because, as the author stated, the prolonged fermentation failed to reduce fructan content. A separate group of LAB was distinguished, called fructophilic $\mathrm{LAB}$, which prefers fructose over glucose as a growth substrate. These bacteria, especially Apilactobacillus kunkeei B23I and Fructobacillus fructosus MBIII5, used in sourdough were found to quickly metabolise fructose and efficiently degrade fructans in the wheat medium [Albiac et al., 2020]. A Finish research group evaluated the effect of LAB-sourdough bread versus traditional yeast sourdough bread on the severance of symptoms in IBS subjects [Laatikainen et al., 2016, 2017].
The consumption of low-FODMAP rye bread, made with LA-sourdough, resulted in a lower incidence of flatulence, abdominal pain, cramps, and stomach rumbling in IBS patients and a lower value of breath hydrogen [Laatikainen et al., 2016]. However, it did not affect the quality of life and symptom severity scoring system (IBS-SSS). Similarly, sourdough wheat bread had a lower content of ATIs and FODMAP as compared to yeast-based wheat bread; however, it did not affect IBS symptoms in a seven-day trial [Laatikainen et al., 2017]. Therefore the authors suggested that bread modification is not enough to reduce symptoms and that the holistic modification of dietary habits is required.

Cereals, including wheat, barley, and rye, are sources of substances triggering allergic and autoimmune disorders. Gliadins, glutenins, and albumin/globulin fraction are involved in IgE-dependent allergic reaction and development of autoimmune diseases, like celiac disease. Selected LAB strains were found to degrade wheat proteins belonging to albumin/globulin and gliadins as well as to hydrolyse IgE-binding epitopes of wheat allergens, potentially reducing the allergenicity of wheat [Stefańska et al., 2016]. Moreover, the 60-day challenge with sweet baked goods made of previously sourdough-fermented flour showed no changes in haematology, serology, and intestinal barrier markers in eight coeliac disease patients in remission [Di Cagno et al., 2010]. This study showed that complete degradation of gluten through fermentation of wheat flour can be a safe option for gluten-free diet followers. The screening of bacterial strains capable of reducing allergenicity has been performed in the last years. A recent study has shown that three strains of LAB, i.e., Pediococcus acidilactici XZ31, Pediococcus pentosaceus GD4, and Lactobacillus sakei GS6, had the highest antiallergic potential [Fu et al., 2020], which can be used in the development of new, hypoallergic products.

\section{LEGUMES}

Legumes are rich sources of particularly desired ingredients like proteins, carbohydrates, dietary fibre, minerals, and phenolic compounds, including isoflavones (IFs). LA-fermentation of legumes brings several advantages since it decreases the content of non-nutritional factors, improves their digestibility, and reduces allergenicity [Çabuk et al., 2018; Frias et al., 2008]. Fermentation also improves the biological activity of legume components for example via protein proteolysis with the release of bioactive peptides [Gibbs et al., 2004], through bioconversion of IFs [de Camargo et al., 2019] or due to the potential of LAB for exopolysaccharide secretion in a matrix of legumes [Li et al., 2014]. Although the nutritional level of soybean is limited by the presence of several substances undesirable from a nutritional point of view, such as ATIs and phytates [Egounlety \& Aworh, 2003], it is the most utilised legume for fermentation. Other legumes like black beans, green beans, peanuts, chickpea or lupine subjected to fermentation are also attractive materials for manufacturing health-beneficial food products.

\section{Safety}

Traditionally fermented soybean foods have a high content of BAs. Mah et al. [2019] reported that soybean-based products 
may contain: tryptamine, $\beta$-phenylethylamine, putrescine, cadaverine, histamine, tyramine, spermidine, and spermine as an effect of staphylococci, Bacillus spp., and LAB strains fermentation. The effect of decarboxylase-positive microorganisms is enhanced by the LAB proteolytic capacity, resulting in a high content of amino acids and finally BAs. Especially putrescine, tyramine, and histamine were detected in almost all analysed samples [Mah et al., 2019]. However, the LAB strains capable of producing an opposite effect are also tested. One of the most promising LAB are starter cultures with amine oxidase activity. Three different classes of oxidases have been described: copper-containing, multi-copper containing, and flavin-containing monoamine oxidases. They catalyse the oxidative deamination of BAs, forming aldehydes, hydrogen peroxide, and ammonia. These oxidases were detected in Bacillus spp. but also in selected strains of Lactobacillus plantarum that are applied for miso production [Lee et al., 2016].

Another issue related to the safety of legume-based fermented products is the change in the immunoreactivity of proteins produced by LAB. Standard starter cultures applied for the fermentation of soy milk contain Lactobacillus and Bifidobacterium strains and for ease, commercial dairy starters are often used for fermentation. This is a risky protocol due to the different composition of raw material, e.g., different carbohydrate composition (legumes contain stachyose, raffinose, sucrose, glucose, and fructose, while dairy sugars include lactose, glucose, and galactose) [Champagne et al., 2009]. It has been already reported that LAB metabolic changes and decreased activity are minor problems compared to the changed expression of bacterial proteins and their further modifications that can cause different immunoreactive LAB features. It was reported that Lactobacillus casei GCRL163 cultured in the conditions of lactose starvation showed the expression of eleven glycolytic enzymes that were differentially regulated. This bacterial survival strategy was responsible for different, expected immune system response to this product [Hussain et al., 2009]. A recent study has confirmed that some shock factors, like the mentioned persistent carbohydrate starvation or extreme acidity in the final product, may up-regulate the expression of bacterial surface proteins (S-protein) in the tested Lactobacillus paracasei GCRL46. The S-protein is homologous to secreted glucan-binding $(\mathrm{GpbB})$ and immunoglobulin-binding (SibA) proteins, which are expressed in pathogenic streptococci and may be immunoreactive with IgE, as are allergenic epitopes [Pepper \& Britz, 2019]. This explains why well-adapted Lactobacillus plantarum strains are very often used for the fermentation of legumes. Therefore, the protective effect on the starter cultures used requires further studies, especially for a demanding matrix the legumes are.

LA fermentation in legume-based products can also reduce the content of mycotoxins (aflatoxin $\mathrm{B}_{1}$, zearalenone, ochratoxin, fumonisins, patulin) and pesticides (glyphosate) but also inhibits the development of pathogens in fermented seeds and sprouts, which was summarised and explained in recent literature reviews [Anal et al., 2020; Licandro et al., 2020].

\section{Probiotic activity}

LAB are usually not considered as the most common bacteria in the traditional fermentation of legumes. In most products, fermentation of legumes is carried out with the use of alkaline fermentation microorganisms [Kwon et al., 2019; Seo et al., 2018]. Still, LA fermentation plays a pivotal role in the development of physicochemical properties and biological activity of legume products. LAB are successfully applied for fermenting soybeans, to obtain soy milk, soy sauce, the Vietnamese tuong, modified Japanese natto, Korean doenjang, and Cambodian sieng [Chen et al., 2021; Jung et al., 2016]. Many LAB strains used for the fermentation of legumes belong to the group of those with probiotic properties; therefore, the ways of maintaining their high count in products are widely explored. The technological process for legume-based, milk-replacing beverages preparation or soy sauce preparation includes boiling for $5 \mathrm{~min}$ or autoclaving at $121^{\circ} \mathrm{C}$ for $15 \mathrm{~min}$ [Li et al., 2014]. All these protocols result in the deactivation of natural microbiota. Thus, various starter cultures based on single strains or mixed co-cultures are used with different efficiencies in achieving adequate probiotic cell numbers.

It has been reported that the addition of Streptococcus and Saccharomyces to the soy milk can enhance the viability of Lactobacillus helveticus R0052 in a mixed culture [Champagne et al., 2009], but the mixed cultures need to be thoroughly tested in terms of their ability to compete in the raw material. Legumes have a moderate buffering capacity, which might affect the application of standard dairy starter cultures like Lactobacillus delbrueckii R0187 and Lactobacillus rhamnosus R0011, and probiotic strains like Bifidobacterium longum R0175 for fermentation. Contrary, studies based on other strains, i.e., Lactobacillus delbrueckii subsp. bulgaricus IM025 and Lactobacillus rhamnosus GG, showed increased bacterial proliferation of those strains and acidic properties in soy milk co-cultured with Streptococcus thermophilus [Farnworth et al., 2007]. Therefore, the effectiveness of fermentation is largely determined by the precise selection of strains in starter cultures for the particular raw material.

The more combined the raw material is, the more complicated co-cultures are needed for fermentation to preserve its biological properties. This regularity was reported in the research on a mixed peanut-soy milk functional beverage fermented with six different LAB strains [Santos et al., 2014]. The peanut and soy milks were mixed in the 2:1 ratio. Desirable parameters for this matrix (appropriate count of bacteria and acidification level) were found in a binary culture of Pediococcus acidilactici UFLABFFCX 27.1 with Lactobacillus acidophilus LACA 4, and in the co-culture of those two with Saccharomyces cerevisiae UFLA YFFBM 18.03. In that raw material, probiotic Lactobacillus strains achieved higher quantity and viability when cultivated with Saccharomyces cerevisiae. LA production for those combinations of strains reached 9.03 and $8.51 \mathrm{~g} / \mathrm{L}$, respectively. Moreover, the reduction of fermentation time by half was observed due to the rapid metabolism of carbohydrates and the formation of free amino acids. The higher content of growth-stimulating metabolites for probiotic Lactobacillus strains enabled reaching $8 \log _{10} \mathrm{CFU} / \mathrm{mL}$ in the product up to $8 \mathrm{~h}$ of fermentation [Santos et al., 2014]. The addition of yeast served as a source of protein and vitamin B, which was previously explained by Rekha \& Vijayalakshmi [2010]. Similar quantity and kinetics of fermentation in mixed 
co-cultures were also noted in products containing Bifidobacterium RBL 00079 that was able to metabolise stachyose in soy milk fermented with co-cultures with Lactobacillus delbruecki subsp. bulgaricus IM 025, in which stachyose content was by two logarithms higher than in the dairy material [Farnworth et al., 2007]. In other studies, LAB assigned to several Lactobacillus sp., including Lactobacillus plantarum, Lactobacillus rhamnosus, and Lactobacillus casei, and 50 other microorganisms grouped in 10 different microbial consortia were tested for the fermentation potential of both the pea protein and pea-milk protein emulsions. In the mixed emulsions, LAB significantly inhibited the growth of Actinobacteria and Proteobacteria but also inhibited Bacillus strains (e.g., Bacillus subtilis and Bacillus licheniformis) [Ben-Harb et al., 2019]. Lactobacillus plantarum strains were the most adapted for the pea protein emulsion fermentation and were able to reach $8.5 \log _{10} \mathrm{CFU} / \mathrm{g}$. The Lactococcus lactis and Lactobacillus casei/rhamnosus group were dominant in the tested consortia preferable for the fermented mixed pea-milk protein emulsion. Their quantity reached $9.1 \log _{10} \mathrm{CFU} / \mathrm{g}$. Moreover, this procedure enabled reducing the level of hexanal, which high content normally leads to an undesired green pea aroma, whereas LA fermentation promoted the release of volatile compounds responsible for a roasted/grilled aroma in the pea protein emulsion, and a fruity, lactic aroma for the pea-milk protein emulsion [Ben-Harb et al., 2019]. In another study, the application of mixed co-cultures for soy milk fermentation brought the antagonistic effect instead of the expected synergistic effect on the growth of bacteria [Champagne et al., 2010]. Nevertheless, the health-promoting effects, manifested by increased IF bioavailability and oligosaccharide digestibility, sustained stronger in mixed cultures. Champagne et al. [2010] reported that fermentation with Lactobacillus helveticus R0052 combined with Streptococcus thermophilus ST5 and Bifidobacterium longum R0175 resulted in the more than a tenfold reduction in R0175 strain viability in comparison to single strain cultures. The combination of those strains was used to achieve an increase in the content of folic acid, niacin, riboflavin, and vitamins $\mathrm{B}_{12}$ and $\mathrm{B}_{6}$, previously suggested by other groups [Mo et al., 2013; Limón et al., 2015].

In the legume fermentation technology, the selection of solid vs. fluid state fermentation has a particularly significant effect on the count and viability, and thus on the probiotic activity of bacteria. In the production of legume-based foodstuff, a favourable solution seems to be co-fermentation using LAB and Bacillus subtilis from natto by solid-state fermentation [Chen et al., 2021]. Chen et al. [2021] reported that after fermentation of lentils, the best growth of LAB was observed in aerobic solid-state co-fermentation, whereby the viable counts of Lactobacillus plantarum TK9 and Lactobacillus paracasei TK1501 reached 8.41 and $8.77 \log _{10} \mathrm{CFU} / \mathrm{g}$, respectively. This study showed that both, the composition of applied strains but also the adjustment of the conditions (aerobic/anaerobic) and the solid/liquid state of the fermentation of legumes were important. The viability of those strains reached 5.90 and $5.23 \log _{10} \mathrm{CFU} / \mathrm{g}$ in anaerobic conditions and 6.61 and $6.5 \log _{10} \mathrm{CFU} / \mathrm{g}$ in the liquid state, respectively. The benefits of solid-state fermentation of soybean meal with Lactobacillus strains and Clostridium butyricum have also been reported [Su et al., 2018]. A successive increase in counts of both bacterial strains was noted during $48 \mathrm{~h}$ of fermentation, reaching $8 \log _{10} \mathrm{CFU} / \mathrm{g}$ at spore production of $6 \log _{10} \mathrm{CFU} / \mathrm{g}$ [Su et al., 2018]. The authors reported also that the $\mathrm{pH}$ value and sugar content (especially raffinose and stachyose) in fermented soybean meal were considerably reduced in the presence of Lactobacillus strains. Furthermore, this newly developed, fermented piglet feed showed antibacterial activity against Staphylococcus aureus and Escherichia coli [Su et al. 2018]. These results suggest that LA fermentation improves the probiotic properties of legume matrix in many ways and that the fermented legumes are beneficial in both human nutrition and animal feeding.

\section{Isoflavones}

IFs belong to flavonoids and are structurally and functionally similar to the human estrogen, estradiol, therefore are called phytoestrogens. Due to this similarity, IFs were suggested to elicit preventive effects in many kinds of hormone-dependent diseases but also to exhibitit a beneficial effect in alleviating menopausal symptoms and minimising their undesirable consequences [Chiang \& Pan, 2011].

Legumes, especially soybean, lentil, broad bean, and chickpea, are the richest sources of IFs [de Camargo et al., 2019]. Their native forms are conjugated with sugars. The $\beta$-glucoside forms are not absorbed and require hydrolysis, which increases their bioavailability and subsequent metabolism [Donkor \& Shah, 2008]. LAB have $\beta$-glucosidase activity and can increase the aglycone IF content in fermented products, and thus they increase IF bioavailability in comparison to unfermented products. The potential of LAB to convert IFs was described by Donkor \& Shah [2008], who reported it in soy milk fermented with Lactobacillus acidophilus LAFTI L10, Bifidobacterium lactis LAFTIB94, and Lactobacillus casei LAFTI L26. These authors observed significant differences between raw $(0.2 \mu \mathrm{g} / \mathrm{mL}$ of aglycones) and fermented soy milk $(0.6 \mu \mathrm{g} / \mathrm{mL})$. However, the rate of conversion did not differ significantly between the tested strains, although the kinetics of conversion was strictly strain-dependent and correlated with the kinetics of bacterial growth. In another study, the size of soybean seeds was suggested to influence the efficacy of conversion and the composition of aglycones during the fermentation with Lactobacillus plantarum strain P1201 [Lee et al., 2018]. Consequently, the content of isoflavone aglycones in all five samples obtained from small-seeded cultivars (average $13.9 \mathrm{~g} / 100$ seeds), namely Pungsannamul, Pungwon, Janggi, Shinhwa, and Heapum, was significantly higher than those from the five medium-seeded cultivars (average $21.4 \mathrm{~g} / 100$ seeds), namely Saedanbaek, Daewon, Daepung, Neulchan, and Taekwang. The most abundant individual aglycone was daidzein (average $26.6 \rightarrow 265.9 \mu \mathrm{g} / \mathrm{g}$, ten times higher conversion), followed by genistein (average $19.9 \rightarrow 169.5 \mu \mathrm{g} / \mathrm{g}, 8.5$ times), and glycitein (average $12.3 \rightarrow 18.2 \mu \mathrm{g} / \mathrm{g}, 1.5$ times).

Another study reported that glucosides, especially in soybean, were derived from three main IFs (daidzein, geninstein, and glycitein) and each could have acetyl and malonyl glucoside conjugates [Champagne et al., 2010]. The deconjugation levels varied between the different glucosides. Moreover, each 
strain had a different potential for deconjugation. Fermentation by Lactobacillus helveticus R0052 resulted in the 50\% reduction in total glucosides of soybeen, with 6-O-malonyl glucosides being reduced by $64 \%$. Fermentation by a single strain of Streptococcus thermophilus ST5 or Bifidobacterium longum R0175 had no significant effect on IF levels. Combining an ST5 strain with a R0052 in the culture reduced the effectiveness of the latter. In another study, five isolates of LAB, Lactobacillus acidophilus B4496, Lactobacillus bulgaricus CFR2028, Lactobacillus casei B1922, Lactobacillus plantarum B4495, and Lactobacillus fermentum B4655 in a combination with yeast Saccharomyces boulardii were used, and the ability to hydrolyse daidzein and genistein in approx. 98\% during $24 \mathrm{~h}$ of fermentation was reported for all co-culture combinations [Rekha \& Vijayalakshmi, 2010]. The authors concluded that the mixed cultures of LAB with non-lactic probiotic yeast Saccharomyces boulardii had a synergic effect on the IFs conversion. Similar results regarding the effects of different LAB co-cultures and the use of seeds from different cultivars have been demonstrated for lentil-based fermented products [Chen et al., 2021]. In this study, the profile of IFs in unfermented green lentil samples was different depending on their origin and was different from the profiles reported for soybean. In general, in the mixed co-cultures of LAB (Lactobacillus plantarum TK9 and Lactobacillus paracasei TK1501) with Bacillus subtilis from natto in the solid-type fermentation, anaerobic conditions were favourable for IFs conversion; however, some strains had a higher conversion activity in aerobic conditions. Alike findings were noted in an experiment where similar processes were monitored for fermented kidney bean extracts [Limón et al., 2015]. The authors reported synergistic conversion activity of Lactobacillus plantarum CECT 748T with Bacillus subtilis CECT 39T in solid-type fermentation. Again, the synergic activity of LAB with Bacillus subtilis to enhance the production of IF aglycones was observed, increasing four-fold the antioxidant activity of fermented legumes [Limón et al., 2015].

Fermentation is also an effective solution in improving the quality of legume seed sprouts that have become popular in recent years. LA fermentation of four types of legume sprouts with Lactobacillus casei 0979 was used to increase the content of IFs and to improve the microbiological safety of the final product [Budryn et al., 2019]. Fermentation of germinated seeds increased five times the content of IFs. The highest content was noted for clover and chickpea sprouts. Furthermore, during fermentation, the count of LAB increased by $2 \log _{10} \mathrm{CFU} / \mathrm{mL}$, that of mould decreased by $1 \log _{10}$, whereas those of E. coli and Klebsiella sp. by $2 \log _{10}$. In turn, Salmonella sp. and Shigella sp. did not occur after fermentation, similarly to Staphylococcus epidermidis, while S. aureus and $S$. saprophyticus counts decreased by $3 \log _{10}$ or were not detected in some samples.

Another interesting issue is the effect of legume-derived IFs after LA fermentation on the gastrointestinal tract. The impact of the intestinal microbiota of host on a consumed product is not fully understood and thus intestinal fermentation can have an uncontrolled impact on IFs conversion and retention. The wide interindividual variability in the bioconversion of IFs is related to specific metabotypes, indicating how IFs are metabolised in humans. Latest data report that fermentation reduces the passive excretion of non-metabolised IFs and can reduce the impact of gut microbiota on further conversion [de Oliveira Silva et al., 2020]. In this study, the authors reported that women excreted higher amounts of colonic metabolites and lower amounts of aglycones than men. The prevalence of $O$-demethylangolensin-producer, equolproducer, and nonproducer metabotypes after consumption of unfermented products (soybean meal biscuits) accounted for 56,11 , and $36 \%$, while after consumption of the fermented product reached 72,11 , and $17 \%$, respectively. It was reported that these gender-microbiota-dependent parameters could influence the beneficial effect of IFs. One of the longitudinal epidemiologic studies indicated a beneficial effect of dietary soybean genistein and daidzein in the prevention of osteoporosis by stimulating bone formation and suppression of bone resorption in the menopausal period of life [Xiao et al., 2018]. Some randomised controlled clinical trials reported the beneficial effect of the daily consumption of fermented and unfermented soy milk products on serum lipid profiles in moderately hypercholesterolemic male participants. Reduced serum levels of total cholesterol, LDL-cholesterol, and non-HDL-cholesterol werereported in the groups receiving IF-supplemented and soy milk fermented with LAB compared to the participants consuming unfermented soy milk [Cavallini et al., 2016].

There are also reports referring to the beneficial effect of IFs from fermented soy milk on carcinogenesis. In a large trial with 306 women with breast cancer and 662 controls, the habitual consumption of soybean IFs fermented with Lactobacillus casei Shirota since adolescence was associated with a reduced risk of breast cancer [Toi et al., 2013]. Moreover, the immunoprotective effect of IFs of soy milk fermented with a mixed culture of 2 strains of Lactobacillus plantarum (DPPMA24W and DPPMASL33), Lactobacillus fermentum DPPMA114, and Lactobacillus rhamnosus DPPMAAZ1 was reported. This product was able to reduce NO release from human Caco-2/TC7 cell lines with induced inflammation with interferon- $\gamma$ (INF- $\gamma$ ) and lipopolysaccharides [Toi et al., 2013]. It was also observed that the treatment with this product succeeded in the reduction of interleukin 8 (IL-8) expression, suggesting a direct beneficial effect of IF aglycones generated during fermentation and the formation of equol from the aglycone daidzein [Di Cagno et al., 2010]. All these health-promoting activities are promising; however, it has to be taken into consideration that many positive effects can be associated with LAB metabolites.

\section{Other phenolic compounds}

Legumes contain also other phenolic compounds different from IFs, such as phenolic acids, flavonols, flavanones, etc., which are responsible for a high antioxidant capacity. Their presence contributes to lowering the risk of diseases caused by oxidative stress, like cancer, cardiovascular and neurodegenerative disorders [Vauzour et al., 2010]. The effect of LA fermentation on the content of phenolics and antioxidant capacity of legumes has been extensively investigated and some mechanisms that were already referred to the section dedicated to fruits and vegetable fermentation are 
actual here. Indeed, the controlled fermentation of legumes with fully-defined starter cultures is more beneficial and safer than the spontaneous fermentation [Licandro et al., 2020]. However, it is more complicated to distinguish the direct role of $\mathrm{LAB}$ in creating the phenolic profile of legumes. The vast majority of studies referred to the significant role of alkaline fermentation of legumes with Rhizopus sp. [Ali et al., 2016] and Bacillus subtilis natto [Duenas et al., 2012] in the production of phenolic compounds. The phenolic profile is also affected by other variables, like material type and process conditions, [Limón et al., 2015].

A study on the impact of LA fermentation with Lactobacillus plantarum CECT 748 on phenolic compounds in soybean and mung bean-based products reported major changes in IFs content, but only in the soybean products [Landete et al., 2015]. Surprisingly, IFs and kaempferol derivatives were not detected in the non-fermented green bean. The compounds detected in mung bean were mainly glycoside forms of flavanones (eriodictyol 7-O-galactoside, eriodictyol 7-O-glucoside) and flavones (apigenin hexose, apigenin 8-C-glucoside, and luteolin 7-O-glucoside) (total content - $486.64 \mu \mathrm{g} / \mathrm{g}$ ), whereas the most abundant compounds extracted after fermentation were apigenin derivatives (apigenin 7-O-glucoside and apigenin 8 - $C$-glucoside), whose content increased from $399.23 \mu \mathrm{g} / \mathrm{g}$ to $1519.98 \mu \mathrm{g} / \mathrm{g}$. Moreover, a significant increase was determined in the contents of eriodictyol 7-O-galactoside from 5.49 to $95.74 \mu \mathrm{g} / \mathrm{g}$ and (+)-catechin derivative from non-detectable to $11.47 \mu \mathrm{g} / \mathrm{g}$. In the case of the soybean-based fermented products, a significant increase was detected in the contents of naringenin from the non-detectable to $7.72 \mu \mathrm{g} / \mathrm{g}$ and kaempferol diglucoside from $12.86 \mu \mathrm{g} / \mathrm{g}$ to $20.21 \mu \mathrm{g} / \mathrm{g}$. Additionally, increased contents of hydroxybenzoic and hydroxycinnamic acids were found [Landete et al. 2015].

A study by Limón et al. [2015] also refers to the applicability of the above-mentioned Lactobacillus plantarum CECT 748 strain in single strain fermentation of kidney beans in comparison to naturally fermented and fermented with Bacillus subtilis products. It has been confirmed that CECT 748 strain hydrolyses $\beta$-glucosidic bonds of several phenolic compounds occurring in a conjugated form (phenolic glucosides) to the corresponding aglycones, increasing the content of free phenolics. A general increase in the content of hydroxycinnamic acid derivatives was observed in the product fermented with this strain. (+)-Catechin content decreased remarkably in all fermented products, reaching levels under the detection limit. The decrease of $(+)$-catechin (monomer) content could be attributed to the formation of procyanidins (flavan-3-ols oligomers) during fermentation. In this study, a significant decrease was reported in flavanone and flavonol contents, by 94 and $78 \%$, respectively. Phenolic compounds in the samples fermented with Bacillus subtilis reached levels under the detection limit [Limón et al., 2015]. Noteworthy, most of the studies referring to the applicability of Lactobacillus strains for legume fermentation used strains of Lactobacillus plantarum which seems to be the most adapted to this matrix. In a study where the DSM 20174 strain was used to ferment grass pea, it was concluded that the observed increase in the level of phenolic compounds during fermentation might be due to the activity of bacterial laccase and peroxidase
[Starzyńska-Janiszewska \& Stodolak, 2011]. Moreover, the drop in $\mathrm{pH}$ upon fermentation could be the factor activating enzymes participating in the hydrolysis of phenolic glycosides and causing their liberation from the lignocellulosic matrix [Çabuk et al., 2018].

It was reported that the augmented amount of phenolic compounds, including phenolic acids, in fermented legumes, especially mung bean and soybean, enhanced their antioxidant, cytotoxic, and immunomodulatory effects evaluated in the in vitro studies on hormone-dependent breast adenocarcinoma MCF-7 and human non-tumorigenic breast MCF 10A cell lines [Ali et al., 2016]. Nevertheless, most of the available research can only partly support the hypothesis that the antioxidant potential is due to the content of phenolics and not to the other antioxidants, including tocopherols, carotenoids, and peptides, released from proteins in fermented products. Regardless of which compounds are responsible for the beneficial effects, the antioxidant potential of legumebased fermented products is significantly higher than that of the non-fermented ones [Limón et al., 2015].

\section{Vitamins, $\gamma$-aminobutyric acid, and other bioactive compounds}

There are many ambiguous results regarding the impact of LA fermentation on the content of vitamins in legume-based products. In general, it is considered that the LA fermentation results in their enrichment with valuable nutritional compounds, like vitamins and minerals. Legumes themselves are a rich source of vitamins, but the increase in their content is mainly through alkaline fermentation using Bacillus subtilis or Rhisopus sp. Mo et al. [2013] showed that the contents of vitamins in soy-based foods, including vitamin $\mathrm{K}_{2}$ in natto and vitamin $\mathrm{B}_{12}$ in tempeh, were higher compared to the non-fermented material. Additionally, indigenous bacteria in soybeans, such as Klebsiella pneumoniae and Citrobacter freundii, which persist the warming up process, have been found to contribute to vitamin $B_{12}$ increase compared to the non-fermented material. Fermentation with LAB can also improve the bioavailability of these vitamins from the product [Mo et al., 2013]. In several studies reported in this manuscript, the content of vitamins $\mathrm{B}_{6}$ and $\mathrm{B}_{12}$ in fermented legume-based products did not increase significantly [Champagne et al., 2009, 2010], except for the fermentation with Saccharomyces boulardii that was able to increase vitamin $\mathrm{B}_{2}$ content in soy milk but failed to increase it in the co-cultures with LAB [Rekha \& Vijayalakshmi, 2010]. One of the studies referring to LAB-fermented soy germ showed that despite the total contents of tocopherols and phytosterol were significantly reduced during fermentation, their antioxidant activity was high [Hubert et al., 2008]. Raw soy germs contained $0.36 \mathrm{mg} / \mathrm{g}$ of total tocopherols, with $47.5 \%$ of $\alpha$-tocopherol, $0.3 \%$ of $\beta$-tocopherol, $2.2 \%$ of $\gamma$-tocopherol, and $50 \%$ of $\delta$-tocopherol. At the end of the fermentation, the total content of tocopherols accounted only for less than $0.08 \mathrm{mg} / \mathrm{g}$. A decreased total phytosterol content, from $4.17 \mathrm{mg} / \mathrm{g}$ to $1.09 \mathrm{mg} / \mathrm{g}$, was also determined after $48 \mathrm{~h}$ of the process. Interestingly, the antioxidant properties of fermented soy germs were significantly improved due to higher contents of saponins, phytosterols, and tocopherols. It was found that $\delta$-tocopherol was the most 
effective in scavenging the DPPH radical with a $74 \%$ absorbance inhibition at a concentration of $0.5 \mathrm{mg} / \mathrm{mL}$, followed by soy germ asapogenol and $\alpha$-tocopherol which showed $44 \%$ and $41 \% \mathrm{DPPH}^{*}$ scavenging activity, respectively, at the same concentration. In the tested products, the conjugation profile of soyasaponins B was modified during the incubation period but the total content of soyasaponins B remained unchanged. The content of 2,3-dihydro-2,5-dihydroxy-6-methyl-4H-pyran-4-one (DDMP)-conjugated soyasaponins decreased drastically from 14.8 to $2.1 \mathrm{~mol} / \mathrm{g}$ when soy germs were fermented, indicating that all the tested LAB strains were able to cleave the DDMP-moieties, releasing maltol, which is often used as a flavour enhancer.

Another beneficial component that accumulates during LA fermentation is GABA. It is a non-protein amino acid produced from L-glutamic acid by glutamic acid decarboxylase (GAD). The potential to synthesise GABA is a strain-dependent feature, and it has been reported that LAB fermentation of legumes, including soybean and kidney bean, allows a significant increase in the content of this compound in fermented material [Limón et al., 2015]. GABA was found to regulate blood pressure, act as a strong secretagogue of insulin from the pancreas, and is considered as an antidepressant since it is a primary neurotransmitter [Del Toro-Barbosa et al., 2020].

Exopolysaccharides (EPS) are one of the bioactive components produced by LAB with a high efficacy in legume-based products. Because of the high content of carbohydrates in the raw material, many LAB strains are able to synthesise EPS loosely connected to the cell surface. The potential prebiotic activity of EPS may enhance the growth of certain microbial strains in the human gut. In addition, EPS have a plenty of other beneficial properties, including antimicrobial, anticancer, antioxidant, and immunomodulatory ones [Wang et al., 2015]. The potential for the production of EPS in fermented legume-based products improves not only the health-promoting properties of the products, but also increases their technological usefulness. The consumption of legumebased beverages fermented with different Lactobacillus strains and fermented dough made of legume flour confers multiple health benefits. The fermentation with LAB strains producing EPS improves rheological properties, viscosity, and sensory values of final products [Li et al., 2014; Xu et al., 2017].

\section{Protein bioavailability and other bioactive effects}

Legumes represent a reach source of nutritious proteins and can restore soil nitrogen without fertilizers; hence, they are considered to be both environmentally and nutritionally friendly. Due to their protein content, they are often recommended in sustainable diets. Both unfermented and fermented legume-based products contain almost all the essential and non-essential amino acids.

Studies on the bioavailability and nutritional content of legume components have also emphasised the benefits of alkaline fermentation to proteins [Bautista-Expósito et al., 2018]. Alkaline $\mathrm{pH}$ is more suitable for the fermentation of various legumes, including soybeans, kidney beans or lentils, but LA fermentation is also widely used due to proteolytic enzymes and amine oxidase activity of LAB. The use of mixed cultures also allows for a shorter fermentation process. It has been reported that the fermentation with Bacillus subtilis or Saccharomyces cerevisiae is longer (over $48 \mathrm{~h}$ ) due to their limited capability to cleave glycoproteins, phosphoproteins or domains containing a high number of disulphide bridges, like in lectins, and that the $\mathrm{LAB}$ can reduce the fermentation time to less than 24 h [Limón et al., 2015; Santos et al., 2014].

Currently, the FAO/WHO defines protein quality in terms of the amino acid profile and digestibility of a protein source based on an in vivo bioassay [FAO, 1991]. The high content of sulfur amino acids inhibits the digestibility of legume proteins. In fermented legume-based products, protein digestibility reaches a maximum even after $5 \mathrm{~h}$ of fermentation $(87.4 \%)$, like in Çabuk et al. study [2018]; however, the score of most of the sulfur amino acids is not reduced. To ensure an optimal reduction in sulfur amino acid content, even 11-h fermentation is needed. The reduction in sulfur content was reported to alter the in vitro protein digestibility from $67.0 \%$ at $0 \mathrm{~h}$ to $54.6 \%$ at $11 \mathrm{~h}$. These data suggest that while fermentation is a viable method for reducing certain non-nutritive compounds in a legume protein concentrate, an alternative bacterium should be used which metabolises sulfur amino acids to a lesser extent than Lactobacillus plantarum [Çabuk et al., 2018]. While soybean-based drinks are currently considered to be the best alternative to cow's milk because of their protein and amino acid content, still almond milk has very little proteins whereas rice and coconut drinks, besides lacking proteins, are also rich in sugar and fat hence, they were fermented with LAB in a limited scale. In terms of the usefulness of proteins, legumes are increasingly used in LA fermentation.

To increase the digestibility of legume proteins, presoaking and hydrolysis with various proteases (papain, bromelain, Veron HPP and Veron PS) followed by fermentation were used [Verni et al., 2020]. It was found that the content of peptides and amino acids of fermented lentil was significantly improved when fermentation was preceded by soaking seeds and hydrolysis, especially with bromelain at the enzyme to substrate ratio of $10 \%$. Although the fermentation generally releases the peptides and amino acids to a small extent, the total free amino acid content (e.g., aspartic acid, glutamic acid, leucine, lysine, and arginine) in pre-treated lentils fermented with Lactobacillus acidophilus ATCC 4356 was shown to increase up to $18 \%$. Verni et al. [2020] reported also a slight increase in the content of Cys and Trp after the fermentation with the mentioned ATCC 4356 and with Lactobacillus fermentum DSM 20052 strains. This finding was promising since all legume storage proteins are relatively poor in sulfurcontaining amino acids (methionine, cysteine) and tryptophan. Unfortunately, a substantial arginine reduction was observed in the DSM 20052 fermented product, probably because the amino acids were used by the strain for growth. A significant increase in GABA (about 20\%) in a Lactobacillus acidophilus ATCC 4356-fermented lentil-based product was noted which was consistent with the results previously reported for kidney bean [Limón et al. 2015]. It was also suggested that the much higher content of free amino acids and peptides had a positive effect on the viability of LAB in the final product and extended its shelf-life [Verni et al., 2020]. In the study of $\mathrm{Hu}$ [2020], the addition of legume protein hydrolysates to 
fermented products increased the content of bacterial biogenic sulfur-containing amino acids and improved LAB viability in the final product. The addition of soybean peptides promoted better properties of dairy-based yoghurt fermented with Streptococcus thermophilus and Lactobacillus delbrueckii subsp. bulgaricus [Hu et al., 2020], which featured a higher content of volatile compounds and better bacterial viability.

Although fermentation with co-cultures has a positive effect on the profile and bioavailability of many biologically-active legume compounds, the use of co-cultures does not positively affect the release of amino acids and peptides from legume proteins. In fermentation of a peanut-soy milk mixture, pure cultures of Saccharomyces cerevisiae UFLA YFFBM18.03, Lactobacillus rhamnosus LR 32, Lactobacillus acidophilus LACA 4, and Pediococcus acidilactici UFLA BFFCX 27.1 promoted the increase in total amino acids (48.02, $47.32,46.21$, and $44.07 \%$, respectively). Among the tested microorganisms, not LAB strains but Saccharomyces cerevisiae was responsible for the greatest accumulation of histidine, lysine, and threonine but also methionine and tryptophan. However, a significant reduction in the content of free amino acids, including essential amino acids, was found in the coculture. It was concluded that these amino acids promoted the growth of bacteria [Santos et al., 2014].

The proteolytic activity of LAB in a legume matrix is also used in the context of nisin production [Liu et al. 2017]. Nisin, a natural antimicrobial peptide, is produced by certain Lactococcus lactis strains, which generally require expensive high-quality nitrogen sources due to their limited ability to biosynthesise amino acids. In the reported study, defatted soybean meal was used as a sole nitrogen source to support nisin overproduction. Both medium optimization in the context of amino acid and peptide contents but also targeted enhancement of the proteolytic function in Lactococcus lactis F44 through rationally expressing the related enzymes were applied [Liu et al. 2017]. Heterologous protease (NprB), an oligopeptide transporter subunit (OppA), and two peptidases (PepF and PepM) were introduced. The constructed strain was capable of achieving efficient biomass accumulation and nisin yield with a 30\% decreased amount of soybean meal hydrolysates [Liu et al., 2017].

A very widely analysed field of knowledge about the role of fermentation in products based on legumes is the production of novel bioactive peptides conferring specific health benefits. Their application in the development of functional foods and pharmaceuticals to replace synthetic drugs in the treatment of several diseases was previously well-reviewed [Sanjukta \& Rai, 2016]. Due to the aforementioned low efficiency of LAB in the proteolysis of legume proteins, LA fermentation is rarely used separately but more often combined with alkaline or completely replaced by it [Nawaz et al., 2017; Wang et al., 2015]. It has been reported that peptides obtained from, e.g., fermented soybean, where the major sources of peptides are glycinin and $\beta$-conglycinin, may act like regulatory compounds and exhibit bioactive properties such as, e.g., antihypertensive, antimicrobial, antioxidant, antidiabetic, and anticancer. It is impossible to list precisely all possible functions, but among the sequences deposited in the databases of bioactive peptides with proven effect, short sequences of di- and tripeptides dominate. The sequences describing the mentioned proteins account for over $95 \%$ of the 303 already reported ones [FeptideDB: Web Application for New Bioactive Peptides from Food Protein].

Peptides obtained from soy milk fermented with Lactobacillus casei strains had strong ACE-inhibitory activity proven both in in vitro and in vivo studies. It was confirmed that the ability to generate health-promoting profiles of peptides is a strongly strain-dependent feature [Bao \& Chi, 2016]. In the study by Bao \& Chi [2016], soy milk fermented with ten different strains was tested in terms of its role in antihypertensive regulation in Wistar-Kyoto rats and spontaneously hypertensive rats. Results showed that soy milk fermented with Lactobacillus casei CICC 20280 and CICC 23184 had high ACE inhibitory activity in in vitro tests. Moreover, the administration of CICC 20280 and CICC 23184 fermented products by gavage could effectively lower the blood pressure of spontaneously hypertensive rats to a normal level, while there was no effect on blood pressure of Wistar-Kyoto rats. It was concluded that, based on multiple control groups with individual components, the bioactive substances responsible for this activity were peptides and GABA. Their contents in CICC 20280 and CICC 23184 fermented products were $3.97 \mathrm{mg} / \mathrm{mL}$ (peptide) and $1.71 \mathrm{mg} / \mathrm{mL}$ (GABA), as well as $5.17 \mathrm{mg} / \mathrm{mL}$ (peptide) and $1.57 \mathrm{mg} / \mathrm{mL}$ (GABA), respectively [Bao \& Chi, 2016].

While searching for new sources of nutritious protein by, e.g., adapting plants, especially legumes, peptides obtained from bean fermentation carried out by Lactobacillus plantarum $299 \mathrm{v}$ also showed very favourable properties [Jakubczyk et al., 2017]. The authors were looking for potential inhibitory peptides of enzymes involved in the metabolic syndrome. They demonstrated that only the fraction with the molecular weight of 3.5-7 $\mathrm{kDa}$ obtained after fermentation at $22^{\circ} \mathrm{C}$ for $3 \mathrm{~h}$ had the $\alpha$-amylase inhibitory activity. The optimal fermentation conditions to release peptides with molecular weights of 3.5-7.0 kDa and the highest lipase or ACE inhibitory activity were determined as $30^{\circ} \mathrm{C}$ and 3 days. The fractions with the highest inhibitory activity were identified by LC-MS/ MS, and eight unique peptides were identified in that fraction. The results reported by these authors also suggest that optimal fermentation process conditions should be selected according to the expected specific activity of peptides [Jakubczyk et al., 2017].

Another study reported the anticarcinogenic effect of soybean powder fermented with Lactobacillus plantarum DGK17, which was previously isolated from kimchi [Khan \& Kang, 2017]. The treatment with a fermented soybean extract reduced cancer cell colony formation, morphological changes, and apoptotic cell death of HCT-116 colon cancer cells in a dose-dependent manner. It also resulted in a weakened mitochondrial membrane potential, which also caused the release of Cyto C, further activating caspase-mediated cancerous cell death. It was concluded that the mechanism of action of the peptide fraction was based on cytosolic and mitochondrial reactive oxygen species sensitization and activation of mitogen-activated protein kinase (JNK) and other apoptotic signaling molecules. Such solutions indicate a great potential that is still to be discovered, while an important issue 
is the careful selection of LAB strains, sometimes the less obvious ones, that could be used for fermentation [Khan \& Kang, 2017].

The role of bacterial selection is particularly important in terms of their ability to reduce allergenicity and immunoreactivity of proteins. As it was mentioned before, although the alkaline fermentation offered a significant potential to eliminate unavailable components of legumes, including reducing the immunoreactivity of major allergens especially in solid-state fermentation type, the LAB are still the most effective in conventional, liquid fermentation [Frias et al., 2008]. It has been a while since Frias et al. [2008] reported that Lactobacillus plantarum-fermented soybean flour showed the highest grade of reduction in IgE-immunoreactivity (96-99\%) depending upon the sensitivity of the human allergic plasma. Among the solid-state fermentation products, those inoculated with Bacillus subtilis yielded an 81 and $86 \%$ reduction in immunoreactivity against both human plasma 97.5 IgE kUA/L and human pooled plasma samples, respectively. A current study conducted by Yang et al. [2018] demonstrated that the solid-state fermentation of a soybean meal by a starter culture containing Lactobacillus casei CGMCC1. 539, yeast, and Bacillus subtilis CICC 20641 affected the allergenicity in in vitro and in vivo studies. Soybean $\beta$-conglycinin and glycinin were degraded into low-molecular-weight polypeptides, in which allergenic epitopic sequences reduced IgE-binding capacity in the in vitro trials with human serum. It was confirmed in an animal model of sensitised BALB/c mice. The treatment with fermented soybean induced reduction of mast cell protease-1 (mMCP-1) level and specific to soybean IgE, and boosted the secretion of IFN- $\gamma$ [Yang et al. 2018]. Analogous results were reported by Xia et al. [2019] in immunised $\mathrm{BALB} / \mathrm{c}$ mice model get after the treatment with soy milk fermented only with LAB: Lactobacillus brevis CICC 23474 and Lactobacillus sp. CICC 23470 strains. IgE, mMCP-1, and Th2-related cytokines were decreased, while IFN- $\gamma$ production increased in spleen cell cultures. However, the intestinal villus was slightly damaged after the challenge [Xia et al., 2019], like in the Yang et al. [2018] study.

The greatest discrepancies in the immunomodulatory and allergenic potential of soybean-based products are observed especially concerning soy sauce and natto. One of the production technologies considers two-step fermentation of mixed soybean and gluten proteins using Aspergillus oryzae and LAB strains. However, after fermentation, the product undergoes several steps of heating and filtration, which contribute to the reduction of its allergenic potential; however, tests with allergic sera have indicated that the soybean allergens were still present in this product after the fermentation. The presence of some residual soybean allergens in different commercial soy sauces, immunostained by patient sera, allowed identifying enhanced immunoreactivity of $\beta$-subunit of $\beta$-conglycinin and oleosin, which are not known as major soybean allergens [Magishi et al., 2017]. It might have been a side effect of fermentation, which caused that some hidden before epitopes became exposed after unfolding the conformational structures of proteins. However, in the context of the previously mentioned increase of IFN- $\gamma$ expression and some abnormalities in epithelial tissue physiology reported by Yang et al. [2018] and Xia et al. [2019], the data about soy sauce properties to induce Th1/Th2 regulation are convergent. On the other hand, the protective role of soy sauce was demonstrated in a mouse model of dextran sulphate sodium (DSS)-induced colitis, where the expression of proinflammatory genes encoding enzymes, such as iNOS and cyclooxygenase-2 (COX-2), was decreased in the colonic mucosa, and the expression of genes encoding proinflammatory cytokines in serum, such as TNF $\alpha$, IFN- $\gamma$, IL-6 and IL-17A, was reduced as well [Song et al., 2014].

In the context of undesirable responses to soybean components after fermentation, the cross-reactivity and role of those products in delayed response should be also mentioned. An IgE-independent response has been reported in the context of poly ( $\gamma$-glutamic acid) (PGA), produced in natto fermented with Bacillus subtilis but also other strains in co-culture. It was reported that PGA caused late-onset anaphylaxis. The possible cross-reactivity might be significant to the sting of cnidarian jellyfish that also contains PGA [Inomata et al., 2018].

Another important issue is also the immunoreactivity of the bacterial proteins in the products. It was reported that in legume-based products, the bacterial proteins from bacterial biomass may gain even $16 \%$ rise during 11-h fermentation [Çabuk et al., 2018]. The last two referred studies, in particular, show how much unknown is still to be verified about the role of proteins in fermented legume-based products.

\section{SEAWEED}

Seaweeds are traditionally consumed in Asian countries as marine vegetables. Despite many changes in taxonomic affiliation, a very large number of seaweed species are still classified within the kingdom Plantae; that is why those species will be refered in this review. More than 140 species of macroalgae are used worldwide as foods and depending on their pigment composition, are classified into red algae (Rhodophyta), green algae (Chlorophyta), and brown algae (Phaeophyta). They contain various beneficial bioactive ingredients but owing to their low content of lipids, high content of polysaccharides, fibres, minerals, vitamins, and abundance of phenolic compounds, seaweeds are known for their antioxidant, anticoagulant, antiinflammatory, anticancer, antihypertensive, antiviral, and antimicrobial activities, which was well-reviewed by Chye et al. [2018]. The primary method to obtain biologically-active compounds from seaweed is chemical extraction but fermentation might be a promising alternative in this respect. LA fermentation improves the digestibility and bioavailability of the seaweed components, but also extends their stability and shelf-life. For some compounds, like fiber and vitamins, spontaneous and alkaline fermentation of seaweed with Aspergillus niger and Mucor sp. through solid-state fermentation were reported to be more efficient [Rodríguez-Jasso et al., 2013]. However, the fermentation of seaweed can be carried out by $\mathrm{LAB}$ or using co-cultures with $\mathrm{LAB}$ strains to improve the sensory attractiveness of new products [Bruhn et al., 2019]. It is also highly probable that studies on the potential role of fermented seaweed compounds might be soon reported due to the growing interest in possible antiviral 
and antibacterial effects of seaweeds reported by traditional Eastern medicine. Due to COVID-19, an increasing number of studies are appearing in this context [Pereira \& Critchley, 2020]. Some antiviral properties of unfermented algae have already been reported in the context of the action of polysaccharides and phlorotannin derivatives in inhibiting polymerase and ribonuclease activities of HIV-1 RT or HSV [Pereira et al., 2004] or in bacterial infections but still not much is known about those agents in fermented products.

\section{Polysaccharides}

Many beneficial properties of seaweed are related to the presence of polysaccharides but their bioavailability is limited due to their polymeric structure. The main constituents of these polysaccharides are fucose, mannose, galactose, and uronic acids depending on the seaweed types, which cross-linked with each other and formed complex structures with a high molecular weight that are resistant to degradation and utilisation by microorganisms. On the other hand, fermentation helps increase the solubility of polysaccharides through depolymerization. Bacterial extracellular enzymes modify or lead to degradation of, e.g., the sulfated polysaccharide of the seaweeds, such as sulfated galactan, or fucans which can then be extracted. The polysaccharides released during fermentation show exceptionally strong anticoagulant properties [Shobharani et al., 2013]. Shobharani et al. [2013] reported that LAB strains (Lactobacillus plantarum MTCC 1328, Lactobacillus fermentum, Pediococcus pentosaceus NCIM 5420, Pediococcus acidilactici NCIM 5424, Enterococcus durans NCIM 5427, and Enterococcus faecium NCIM 5363) of marine origin applied for the fermentation of Sargassum sp. caused an increase in the anticoagulating activity of preparations as compared with the control. The enhanced anticoagulating activity was found to be positively correlated with the total sugar content, indicating the role of polysaccharides in inhibiting coagulation cascade. Moreover, LAB cell quantity $\left(8-9 \log _{10} \mathrm{CFU} / \mathrm{mL}\right)$ and viability were reported to be surprisingly high and long, up to 12 days, during which the LA production was high. It was also reported that the increased production of LA in seaweed-based formulas could contribute to the reduction of the molecular mass of alginates without compromising their desired bioactivity [Ramnani et al., 2012]. The selection of LAB strains with limited acidifying properties in that context was a limiting agent in previous studies and resulted in the discrimination of LA fermentation as an effective method to isolate alginate. Ramnani et al. [2012] reported that some low molecular weight polysaccharides derived from agar and alginate-bearing seaweeds in acidified conditions exhibited great potential to be used as a novel source of prebiotics and caused a significant increase in bifidobacteria populations from 8.06 at $0 \mathrm{~h}$ to $8.55 \log _{10} \mathrm{CFU} / \mathrm{mL}$ at $24 \mathrm{~h}(\mathrm{p}=0.018)$.

One of the reported fermented seaweed polysaccharide activities is their radio-protective effect. For this purpose, Ecklonia cava fermented with Lactobacillus brevis, Saccharomyces cerevisiae, and Candida utilis was used for the treatment of $\gamma$-ray-irradiated peripheral immune cells - splenocytes. It was proven that the application of polysaccharides isolated from the $>30 \mathrm{kDa}$ fraction, stimulated proliferation and reduced the number of apoptotic and necrotic cells, as well as markedly reduced the DNA damage and production of reactive oxygen species. Ecklonia cava fermented with LAB showed the strongest DNA protective activity [Lee et al., 2013]. Hence, it may be concluded that fermentation significantly improves the protective and probiotic properties of seaweed.

\section{Phenolic compounds}

Seaweeds are a rich source of phenolic compounds that are secondary defence metabolites synthesised by macroalgae in response to stress conditions. They have a whole spectrum of proven biological activities including antiinflammatory, antioxidant, and antidiabetic ones [Chye et al., 2018; Gupta \& Abu-Ghannam, 2012]. LAB used for the fermentation of seaweeds are reported to be capable of metabolising phenolic compounds, which on the one hand reduces their content, and on the other hand, improves their bioavailability [Chye et al., 2018]. Several studies reported that in different seaweeds, like Sargassum sp., Zostera marina, Himanthalia elongata, Laminaria digitata, and Laminaria saccharina, the Lactobacillus-fermentable caffeic acid, $p$-coumaric acid, and ferulic acids are metabolised into their respective vinyl and ethyl derivatives [Gupta \& Abu-Ghannam, 2011; Rianingsih \& Sumardianto, 2020]. In the study of Rianingsih \& Sumardianto [2020], fermented Sargassum sp. has been reported to be a promising material to produce a non-dairy probiotic beverage. The Lactobacillus plantarum 0027 and Lactobacillus acidophilus FNCC-0051 LAB strains used for fermentation were able to grow by $1 \log _{10}$ during $24 \mathrm{~h}$ of fermentation of a seaweed:water homogenate $(1: 12 \mathrm{v} / \mathrm{v})$. Moreover, $\mathrm{LAB}$ were capable of increasing the count of probiotic cells to $>8 \log _{10} \mathrm{CFU} / \mathrm{mL}$ but also to double the final total content of phenolic compounds compared to the non-fermented products. Importantly, fermentation with FNCC-0051 resulted in greater antioxidant activity, tested with the DPPH assay, than the fermentation with 0027 [Rianingsih \& Sumardianto, 2020]. The metabolism of phenolic compounds in Sargassum sp. fermented with different strains of marine-isolated LAB differed significantly depending on the strain applied [Shobharani et al., 2013]. The viability and activity of strains remained high up to 12 and even 18 days. Under the optimal fermentation period, the seaweed fermented with Enterococcus faecium P1-2CB-w1 exhibited the maximum antioxidant activity, tested with seven different assys, including ABTS and $\mathrm{DPPH}$, which was positively correlated to the content of phenolics ( $\mathrm{r}=0.82-0.92)$ [Shobharani et al., 2013].

Another beneficial activity of seaweed phenolic compounds regulated by LA fermentation is the colon-protective phlorotannin activity. It was tested both in the context of metabolism of these compounds in fermented products, but also in the context of their fermentation by intestinal microbiota [Charoensiddhi et al., 2016]. On the one hand, the LA fermentation seemed to result in a significant decrease in the content of phlorotannins in a fermented brown seaweed Ascophyllum nodosum and a reduced antioxidant capacity of the extracts noted in the ABTS assay but, on the other hand, the antigenotoxic activity and cell growth inhibitory effect in colon HT-29 cells was maintained and enhanced especially for 
the high molecular weight fraction of phlorotannins extracted after fermentation [Corona et al., 2017].

Phenolics, such as phlorotannins, flavonoids, and phenolic acids, and their derivatives from seaweeds are already used in the treatment of diseases, especially those related to oxidative stress. Therefore, further studies on their fate after LA fermentation of seaweed are needed.

\section{Protein and peptides}

The quality of algae protein is relatively high compared to cereal and soybean proteins. More than $75 \%$ of seaweeds belonging to the Plantae kingdom have a higher relative content of protein essential amino acids than wheat flour and 50\% higher than soybean, rice, and corn flours [Mæhre et al., 2014]. The relative content of methionine and lysine was comparable to their content in protein of traditional food-plants. The main limitation in using seaweed as a protein source is its lower content than in corn or soybean. Total protein content varies from about 10 to $40 \mathrm{~g} / 100 \mathrm{~g}$ of seaweeds dry weight, and differs between seasons and species. The highest protein content in seaweed is found in the winter-early spring period, while not in the summer [Mæhre et al., 2014]. Moreover, the content of proteins in the fermented biomass of seaweed increases significantly due to bacterial protein production [Rianingsih \& Sumardianto, 2020].

Bioactive peptides can be released from seaweed proteins by proteases. Seaweed-derived peptides are known for their antioxidant, anticarcinogenic, renin inhibitory, and antihypertensive activities [Cian et al., 2016; Fitzgerald et al., 2014], but not much is known about the direct role of LA fermentation in their release.

It is worth noting that among seaweed proteins, the presence of lectins might be important. Lectins are glycoproteins involved in many biological processes, like intercellular communication. They can agglutinate red blood cells but are also strong mitogens especially for B and $\mathrm{T}$ lymphocytes. Although algae seem to feature a low sensitising potential, a few case studies referred to hypersensitive reactions after seaweeds consumption [Thomas et al., 2019]. One of the indicated reasons may be the homology between seaweed lectins and those identified in some legumes, including peanuts, where they are reported to have the allergenic potential [Goodman, 2020]. LA fermentation may hypothetically reduce the allergenic potential. On the other hand, algal lectins exhibit plenty of bioactive properties, including antibiotic, cytotoxic, antinociceptive, antiinflammatory, antiadhesive, and antiviral ones [Singh et al., 2015].

\section{SUMMARY AND FUTURE PERSPECTIVES}

Fermented food products are gaining attention, not only due to their preservation feasibility and sensory attributes but also because of their nutritional quality and health-promoting potential. The probiotic properties of LA-fermented dairy products are well-established, while the parallel technology for plant-based products is much less developed. However, this review has shown that the area of LA fermentation of plants affords enormous opportunities for new, functional food developments. And although the biotransformation of several nutrients and bioactive compounds and the strain-dependent properties need more in-depth elucidation in several matrices, the recently published research proved that LAB-fermented cereals, fruits, vegetables, legumes, and seaweeds are a good source of health-promoting and nutritional molecules. The obtained products offer a fine alternative for a growing number of vegans, vegetarians, and flexitarians, who look for the plant-based, healthy alternatives. On the other hand, the process of fermentation should be properly designed and controlled to avoid diminishing product's quality and prevent risk to health.

Further studies are needed to evaluate the effect of the intake of LA-fermented foodstuff on the human health in clinical trials since the effects of fermented food are likely to be different than coupled activties of individual bioactive compounds, nutrients, and microbes. Moreover, the survival of probiotic strains in the human gut and the host-microbe interactions need comprehensive, fundamental research. And even though the human studies are limited, the emerging evidence shows that the health benefits of LA-fermented plant-based food products are well-beyond the native materials.

\section{ORCID IDs}

N. Drabińska https://orcid.org/0000-0001-5324-5982 A.M. Ogrodowczyk https://orcid.org/0000-0001-7350-4072

\section{REFERENCES}

1. Acín Albiac, M., Di Cagno, R., Filannino, P., Cantatore, V., Gobbetti, M. (2020). How fructophilic lactic acid bacteria may reduce the FODMAPs content in wheat-derived baked goods: a proof of concept. Microbial Cell Factories, 19(1), art. no.182. https://doi.org/10.1186/s12934-020-01438-6

2. Adebo, O.A., Kayitesi, E., Njobeh, P.B. (2019). Reduction of mycotoxins during fermentation of whole grain sorghum to whole grain ting (a Southern African food). Toxins, 11(3), art. no. 180. https://doi.org/10.3390/toxins11030180

3. Adebo, O.A., Njobeh, P.B., Kayitesi, E. (2018). Fermentation by Lactobacillus fermentum strains (singly and in combination) enhances the properties of ting from two whole grain sorghum types. Journal of Cereal Science, 82, 49-56. https://doi.org/10.1016/j.jcs.2018.05.008

4. Alan, Y., Topalcengiz, Z., Dığrak, M. (2018). Biogenic amine and fermentation metabolite production assessments of Lactobacillus plantarum isolates for naturally fermented pickles. $L W T-$ Food Science and Technology, 98, 322-328.

https://doi.org/10.1016/j.lwt.2018.08.067

5. Ali, N.M., Yeap, S.-K., Yusof, H.M., Beh, B.-K., Ho, W.-Y., Koh, S.-P., Abdullah, M.P., Alitheen, N.B., Long, K. (2016). Comparison of free amino acids, antioxidants, soluble phenolic acids, cytotoxicity and immunomodulation of fermented mung bean and soybean. Journal of the Science of Food and Agriculture, 96(5), 1648-1658.

https://doi.org/10.1002/jsfa.7267

6. Allendez, G.N., Alzogaray, M.S.L., Nazareno, M.A., Gupta, C. (2020). Lactic acid fermentation as a tool to enhance the antioxidant properties of Opuntia ficus-indica juice. Indian Journal of Agricultural Biochemistry, 33(1), 20-24.

https://doi.org/10.5958/0974-4479.2020.00003.9 
7. Anal, A.K., Perpetuini, G., Petchkongkaew, A., Tan, R., Avallone, S., Tofalo, R., Nguyen, H. Van, Chu-Ky, S., Ho, P.H., Phan, T.T., Waché, Y. (2020). Food safety risks in traditional fermented food from South-East Asia. Food Control, 109, art. no. 106922. https://doi.org/10.1016/j.foodcont.2019.106922

8. Bao, Z., Chi, Y. (2016). In vitro and in vivo assessment of angiotensin-converting enzyme (ACE) inhibitory activity of fermented soybean milk by Lactobacillus casei strains. Current Microbiology, 73(2), 214-219. https://doi.org/10.1007/s00284-016-1051-7

9. Barbu, V., Cotârleț, M., Bolea, C.A., Cantaragiu, A., Andronoiu, D.G., Bahrim, G.E., Enachi, E. (2020). Three types of beetroot products enriched with lactic acid bacteria. Foods (Basel, Switzerland), 9(6), art. no. 786.

https://doi.org/10.3390/foods9060786

10. Bartkiene, E, Vidmantiene, D., Juodeikiene, G., Viskelis, P., Urbonaviciene, D. (2013). Lactic acid fermentation of tomato: Effects on cis/trans lycopene isomer ratio, $\beta$-carotene mass fraction and formation of $\mathrm{L}(+)$ - and $\mathrm{D}(-)$-lactic acid. Food Technology and Biotechnology, 51(4), 471-478.

11. Bartkiene, E., Bartkevics, V., Pugajeva, I., Krungleviciute, V., Mayrhofer, S., Domig, K. (2017). The contribution of P. acidilactici, L. plantarum, and L. curvatus starters and L-(+)-lactic acid to the acrylamide content and quality parameters of mixed rye wheat bread. LWT - Food Science and Technology, 80, 43-50. https://doi.org/10.1016/j.lwt.2017.02.005

12. Bartkiene, E., Lele, V., Ruzauskas, M., Domig, K.J., Starkute, V., Zavistanaviciute, P., Bartkevics, V., Pugajeva, I., Klupsaite, D., Juodeikiene, G., Mickiene, R., Rocha, J.M. (2019). Lactic acid bacteria isolation from spontaneous sourdough and their characterization including antimicrobial and antifungal properties evaluation. Microorganisms, 8(1), art. no. 64 .

https://doi.org/10.3390/microorganisms8010064

13. Bautista-Expósito, S., Peñas, E., Silván, J.M., Frias, J., Martínez-Villaluenga, C. (2018). pH-controlled fermentation in mild alkaline conditions enhances bioactive compounds and functional features of lentil to ameliorate metabolic disturbances. Food Chemistry, 248, 262-271.

https://doi.org/10.1016/j.foodchem.2017.12.059

14. Ben-Harb, S., Saint-Eve, A., Panouillé, M., Souchon, I., Bonnarme, P., Dugat-Bony, E., Irlinger, F. (2019). Design of microbial consortia for the fermentation of pea-protein-enriched emulsions. International Journal of Food Microbiology, 293, 124-136. https://doi.org/10.1016/j.ijfoodmicro.2019.01.012

15. Blajman, J.E., Vinderola, G., Páez, R.B., Signorini, M.L. (2020). The role of homofermentative and heterofermentative lactic acid bacteria for alfalfa silage: a meta-analysis. The Journal of Agricultural Science, 158(1-2), 107-118.

https://doi.org/10.1017/S0021859620000386

16. Bruhn, A., Brynning, G., Johansen, A., Lindegaard, M.S., Sveigaard, H.H., Aarup, B., Fonager, L., Andersen, L.L., Rasmussen, M.B., Larsen, M.M., Elsser-Gravesen, D., Børsting, M.E. (2019). Fermentation of sugar kelp (Saccharina latissima) —effects on sensory properties, and content of minerals and metals. Journal of Applied Phycology, 31 (5), 3175-3187. https://doi.org/10.1007/s10811-019-01827-4

17. Budryn, G., Klewicka, E., Grzelczyk, J., Gałązka-Czarnecka, I., Mostowski, R. (2019). Lactic acid fermentation of legume seed sprouts as a method of increasing the content of isoflavones and reducing microbial contamination. Food Chemistry, 285, 478-484.

https://doi.org/10.1016/j.foodchem.2019.01.178

18. Çabuk, B., Nosworthy, M.G., Stone, A.K., Korber, D.R., Tanaka, T., House, J.D., Nickerson, M.T. (2018). Effect of fermentation on the protein digestibility and levels of non-nutritive compounds of pea protein concentrate. Food Technology and Biotechnology, 56(2), 257-264.

https://doi.org/10.17113/ftb.56.02.18.5450

19. Cai, Y.X., Wang, J.H., McAuley, C., Augustin, M.A., Terefe, N.S. (2019). Fermentation for enhancing the bioconversion of glucoraphanin into sulforaphane and improve the functional attributes of broccoli puree. Journal of Functional Foods, 61, art. no. 103461. https://doi.org/10.1016/j.jff.2019.103461

20. Cavallini, D.C.U., Manzoni, M.S.J., Bedani, R., Roselino, M.N., Celiberto, L.S., Vendramini, R.C., de Valdez, G.F., Abdalla, D.S.P., Pinto, R.A., Rosetto, D., Valentini, S.R., Rossi, E.A. (2016). Probiotic soy product supplemented with isoflavones improves the lipid profile of moderately hypercholesterolemic men: a randomized controlled trial. Nutrients, 8(1), art. no. 52 . https://doi.org/10.3390/nu8010052

21. Chaichian, S., Moazzami, B., Sadoughi, F., Haddad Kashani, H., Zaroudi, M., Asemi, Z. (2020). Functional activities of beta-glucans in the prevention or treatment of cervical cancer. Journal of Ovarian Research, 13(1), art. no. 24.

https://doi.org/10.1186/s13048-020-00626-7

22. Champagne, C.P., Green-Johnson, J., Raymond, Y., Barrette, J., Buckley, N. (2009). Selection of probiotic bacteria for the fermentation of a soy beverage in combination with Streptococcus thermophilus. Food Research International, 42(5-6), 612-621. https://doi.org/10.1016/j.foodres.2008.12.018

23. Champagne, C.P., Tompkins, T.A., Buckley, N.D., Green-Johnson, J.M. (2010). Effect of fermentation by pure and mixed cultures of Streptococcus thermophilus and Lactobacillus helveticus on isoflavone and B-vitamin content of a fermented soy beverage. Food Microbiology, 27(7), 968-972. https://doi.org/10.1016/j.fm.2010.06.003

24. Charoensiddhi, S., Conlon, M.A., Vuaran, M.S., Franco, C.M.M., Zhang, W. (2016). Impact of extraction processes on prebiotic potential of the brown seaweed Ecklonia radiata by in vitro human gut bacteria fermentation. Journal of Functional Foods, 24, 221-230. https://doi.org/10.1016/j.jff.2016.04.016

25. Chen, K., Gao, C., Han, X., Li, D., Wang, H., Lu, F. (2021). Co-fermentation of lentils using lactic acid bacteria and Bacillus subtilis natto increases functional and antioxidant components. Journal of Food Science, 86(2), 475-483.

https://doi.org/10.1111/1750-3841.15349

26. Chen, Y., Ouyang, X., Laaksonen, O., Liu, X., Shao, Y., Zhao, H., Zhang, B., Zhu, B. (2019). Effect of Lactobacillus acidophilus, Oenococcus oeni, and Lactobacillus brevis on composition of bog bilberry juice. Foods (Basel, Switzerland), 8(10), art. no. 430. https://doi.org/10.3390/foods8100430

27. Chiang, S.-S., Pan, T.-M. (2011). Antiosteoporotic effects of Lactobacillus-fermented soy skim milk on bone mineral density and the microstructure of femoral bone in ovariectomized mice. Journal of Agricultural and Food Chemistry, 59(14), 7734-7742. https://doi.org/10.1021/jf2013716 
28. Chiş, M.S., Păucean, A., Man, S.M., Vodnar, D.C., Teleky, B.-E., Pop, C.R., Stan, L., Borsai, O., Kadar, C.B., Urcan, A.C., Muste, S. (2020). Quinoa sourdough fermented with Lactobacillus plantarum ATCC 8014 designed for gluten-free muffins-a powerful tool to enhance bioactive compounds. Applied Sciences, 10 (20), art. no. 7140 .

https://doi.org/10.3390/app10207140

29. Chye, F.Y., Ooi, P.W., Ng, S.Y., Sulaiman, M.R. (2018). Fermentation-derived bioactive components from Seaweeds: Functional properties and potential applications. Journal of Aquatic Food Product Technology, 27(2), 144-164.

https://doi.org/10.1080/10498850.2017.1412375

30. Cian, R.E., Garzón, A.G., Ancona, D.B., Guerrero, L.C., Drago, S.R. (2016). Chelating properties of peptides from red seaweed Pyropia columbina and its effect on iron bio-accessibility. Plant Foods for Human Nutrition, 71(1), 96-101.

https://doi.org/10.1007/s11130-016-0533-x

31. Cirlini, M., Ricci, A., Galaverna, G., Lazzi, C. (2020). Application of lactic acid fermentation to elderberry juice: Changes in acidic and glucidic fractions. LWT - Food Science and Technology, 118 , art. no. 108779.

https://doi.org/10.1016/j.Iwt.2019.108779

32. Ciska, E., Drabińska, N., Narwojsz, A., Honke, J. (2016). Stability of glucosinolates and glucosinolate degradation products during storage of boiled white cabbage. Food Chemistry, 203, 340-347. https://doi.org/10.1016/j.foodchem.2016.02.079

33. Ciska, E., Verkerk, R., Honke, J. (2009). Effect of boiling on the content of ascorbigen, indole-3-carbinol, indole-3-acetonitrile, and 3,3'-diindolylmethane in fermented cabbage. Journal of Agricultural and Food Chemistry, 57(6), 2334-2338. https://doi.org/10.1021/jf803477w

34. Conte, P., Fadda, C., Drabińska, N., Krupa-Kozak, U. (2019). Technological and nutritional challenges, and novelty in gluten-free breadmaking: A review. Polish Journal of Food and Nutrition Sciences, 69(1), 5-21. https://doi.org/10.31883/pjfns-2019-0005

35. Corona, G., Coman, M.M., Guo, Y., Hotchkiss, S., Gill, C., Yaqoob, P., Spencer, J.P.E., Rowland, I. (2017). Effect of simulated gastrointestinal digestion and fermentation on polyphenolic content and bioactivity of brown seaweed phlorotannin-rich extracts. Molecular Nutrition and Food Research, 61(11), art. no. 1700223 .

https://doi.org/10.1002/mnfr.201700223

36. Cvetković, D., Ranitović, A., Savić, D., Joković, N., Vidaković, A., Pezo, L., Markov, S. (2019). Survival of wild strains of Lactobacilli during kombucha fermentation and their contribution to functional characteristics of beverage. Polish Journal of Food and Nutrition Sciences, 69(4), 407-415. https://doi.org/10.31883/pjfns/112276

37. Czyżowska, A., Klewicka, E., Libudzisz, Z. (2006). The influence of lactic acid fermentation process of red beet juice on the stability of biologically active colorants. European Food Research and Technology, 223(1), 110-116.

https://doi.org/10.1007/s00217-005-0159-y

38. Czyżowska, A., Siemianowska, K., Śniadowska, M., Nowak, A. (2020). Bioactive compounds and microbial quality of stored fermented red beetroots and red beetroot juice. Polish Journal of Food and Nutrition Sciences, 70(1), 35-44.

https://doi.org/10.31883/pjfns/116611
39. Da Silva Felício, M.T., Hald, T., Liebana, E., Allende, A., Hugas, M., Nguyen-The, C., Johannessen, G.S., Niskanen, T., Uyttendaele, M., McLauchlin, J. (2015). Risk ranking of pathogens in ready-to-eat unprocessed foods of non-animal origin (FoNAO) in the EU: Initial evaluation using outbreak data (2007-2011). International Journal of Food Microbiology, 195, 9-19. https://doi.org/10.1016/j.ijfoodmicro.2014.11.005

40. De Angelis, M., Montemurno, E., Vannini, L., Cosola, C., Cavallo, N., Gozzi, G., Maranzano, V., Di Cagno, R., Gobbetti, M., Gesualdo, L. (2015). Effect of whole-grain barley on the human fecal microbiota and metabolome. Applied and Environmental Microbiology, 81(22), 7945-7956.

https://doi.org/10.1128/AEM.02507-15

41. de Camargo, A.C., Favero, B.T., Morzelle, M.C., Franchin, M., Alvarez-Parrilla, E., de la Rosa, L.A., Geraldi, M.V., Maróstica Júnior, M.R., Shahidi, F., Schwember, A.R. (2019). Is chickpea a potential substitute for soybean? Phenolic bioactives and potential health benefits. International Journal of Molecular Sciences, 20(11), art. no. 2644.

https://doi.org/10.3390/ijms20112644

42. de la Fuente, B., Luz, C., Puchol, C., Meca, G., Barba, F.J. (2021). Evaluation of fermentation assisted by Lactobacillus brevis POM, and Lactobacillus plantarum (TR-7, TR-71, TR-14) on antioxidant compounds and organic acids of an orange juice-milk based beverage. Food Chemistry, 343, art. no. 128414. https://doi.org/10.1016/j.foodchem.2020.128414

43. de Oliveira, S.D., Araújo, C.M., Borges, G. da S.C., Lima, M. dos S., Viera, V.B., Garcia, E.F., de Souza, E.L., de Oliveira, M.E.G. (2020). Improvement in physicochemical characteristics, bioactive compounds and antioxidant activity of acerola (Malpighia emarginata D.C.) and guava (Psidium guajava L.) fruit byproducts fermented with potentially probiotic lactobacilli. $L W T-$ Food Science and Technology, 134, art. no. 110200.

https://doi.org/10.1016/j.Iwt.2020.110200

44. de Oliveira Silva, F., Lemos, T.C.C., Sandôra, D., Monteiro, M., Perrone, D. (2020). Fermentation of soybean meal improves isoflavone metabolism after soy biscuit consumption by adults. Journal of the Science of Food and Agriculture, 100 (7), 2991-2998. https://doi.org/10.1002/jsfa.10328

45. Del Toro-Barbosa, M., Hurtado-Romero, A., Garcia-Amezquita, L.E., García-Cayuela, T. (2020). Psychobiotics: mechanisms of action, evaluation methods and effectiveness in applications with food products. Nutrients, 12(12), art. no. 3896.

https://doi.org/10.3390/nu12123896

46. Di Cagno, R., Barbato, M., Di Camillo, C., Rizzello, C.G., De Angelis, M., Giuliani, G., De Vincenzi, M., Gobbetti, M., Cucchiara, S. (2010). Gluten-free sourdough wheat baked goods appear safe for young celiac patients: a pilot study. Journal of Pediatric Gastroenterology and Nutrition, 51 (6), 777-783. https://doi.org/10.1097/MPG.0b013e3181f22ba4

47. Di Cagno, R., Coda, R., De Angelis, M., Gobbetti, M. (2013). Exploitation of vegetables and fruits through lactic acid fermentation. Food Microbiology, 33(1), 1-10. https://doi.org/10.1016/j.fm.2012.09.003

48. Di Cagno, R., Filannino, P., Vincentini, O., Lanera, A., Cavoski, I., Gobbetti, M. (2016). Exploitation of Leuconostoc mesenteroides strains to improve shelf life, rheological, sensory and functional features of prickly pear (Opuntia ficus-indica L.) fruit puree. Food Microbiology, 59, 176-189. https://doi.org/10.1016/j.fm.2016.06.009 
49. Di Cagno, R., Mazzacane, F., Rizzello, C.G., Vincentini, O., Silano, M., Giuliani, G., De Angelis, M., Gobbetti, M. (2010). Synthesis of isoflavone aglycones and equol in soy milks fermented by food-related lactic acid bacteria and their effect on human intestinal Caco-2 cells. Journal of Agricultural and Food Chemistry, 58(19), 10338-10346.

https://doi.org/10.1021/jf101513r

50. Donkor, O.N., Shah, N.P. (2008). Production of $\beta$-glucosidase and hydrolysis of isoflavone phytoestrogens by Lactobacillus acidophilus, Bifidobacterium lactis, and Lactobacillus casei in soymilk. Journal of Food Science, 73(1), M15-M20.

https://doi.org/10.1111/j.1750-3841.2007.00547.x

51. Duenas, M., Hernandez, T., Robredo, S., Lamparski, G., Estrella, I., Munoz, R. (2012). Bioactive phenolic compounds of soybean (Glycine max cv. Merit): modifications by different microbiological fermentations. Polish Journal of Food and Nutrition Sciences, 62(4), 241-250.

https://doi.org/10.2478/v10222-012-0060-x

52. Egounlety, M., Aworh, O.C. (2003). Effect of soaking, dehulling, cooking and fermentation with Rhizopus oligosporus on the oligosaccharides, trypsin inhibitor, phytic acid and tannins of soybean (Glycine max Merr.), cowpea (Vigna unguiculata L. Walp) and groundbean (Macrotyloma geocarpa Harms). Journal of Food Engineering, 56(2-3), 249-254.

https://doi.org/10.1016/S0260-8774(02)00262-5

53. El Khoury, D., Cuda, C., Luhovyy, B.L., Anderson, G.H. (2012). Beta glucan: health benefits in obesity and metabolic syndrome. Journal of Nutrition and Metabolism, 2012, art. no. 851362. https://doi.org/10.1155/2012/851362

54. Esteban-Torres, M., Landete, J.M., Reverón, I., Santamaría, L., de las Rivas, B., Muñoz, R. (2015). A Lactobacillus plantarum esterase active on a broad range of phenolic esters. Applied and Environmental Microbiology, 81(9), 3235-3242.

https://doi.org/10.1128/AEM.00323-15

55. FAO. (1991). Protein quality evaluation: report of the joint FAO/ WHO expert consultation. Food and Nutrition Paper, 92.

56. Farnworth, E.R., Mainville, I., Desjardins, M.-P., Gardner, N., Fliss, I., Champagne, C. (2007). Growth of probiotic bacteria and bifidobacteria in a soy yogurt formulation. International Journal of Food Microbiology, 116(1), 174-181.

https://doi.org/10.1016/j.ijfoodmicro.2006.12.015

57. FeptideDB: Web application for new bioactive peptides from food protein. http://www4g.biotec.or.th/FeptideDB/

58. Filannino, P., Azzi, L., Cavoski, I., Vincentini, O., Rizzello, C.G., Gobbetti, M., Di Cagno, R. (2013). Exploitation of the health-promoting and sensory properties of organic pomegranate ( $P u$ nica granatum $\mathrm{L}$.) juice through lactic acid fermentation. International Journal of Food Microbiology, 163(2-3), 184-192. https://doi.org/10.1016/j.ijfoodmicro.2013.03.002

59. Filannino, P., Bai, Y., Di Cagno, R., Gobbetti, M., Gänzle, M.G. (2015). Metabolism of phenolic compounds by Lactobacillus spp. during fermentation of cherry juice and broccoli puree. Food Microbiology, 46, 272-279.

https://doi.org/10.1016/j.fm.2014.08.018

60. Filannino, P., Gobbetti, M., De Angelis, M., Di Cagno, R. (2014). Hydroxycinnamic acids used as external acceptors of electrons: an energetic advantage for strictly heterofermentative lactic acid bacteria. Applied and Environmental Microbiology, 80(24), 7574-7582. https://doi.org/10.1128/AEM.02413-14
61. Fitzgerald, C., Aluko, R.E., Hossain, M., Rai, D.K., Hayes, M. (2014). Potential of a renin inhibitory peptide from the red seaweed Palmaria palmata as a functional food ingredient following confirmation and characterization of a hypotensive effect in spontaneously hypertensive rats. Journal of Agricultural and Food Chemistry, 62(33), 8352-8356.

https://doi.org/10.1021/jf500983n

62. Frias, J., Song, Y.S., Martínez-Villaluenga, C., De Mejia, E.G., Vidal-Valverde, C. (2008). Immunoreactivity and amino acid content of fermented soybean products. Journal of Agricultural and Food Chemistry, 56(1), 99-105.

https://doi.org/10.1021/jf072177j

63. Fu, W., Rao, H., Tian, Y., Xue, W. (2020). Bacterial composition in sourdoughs from different regions in China and the microbial potential to reduce wheat allergens. $L W T$ - Food Science and Technology, 117, art. no. 108669.

https://doi.org/10.1016/j.Iwt.2019.108669

64. Garai, G., Dueñas, M.T., Irastorza, A., Moreno-Arribas, M.V. (2007). Biogenic amine production by lactic acid bacteria isolated from cider. Letters in Applied Microbiology, 45 (5), 473-478. https://doi.org/10.1111/j.1472-765X.2007.02207.x

65. Garcia, C., Guerin, M., Souidi, K., Remize, F. (2020). Lactic fermented fruit or vegetable juices: past, present and future. Beverages, $6(1)$, art. no. 8 .

https://doi.org/10.3390/beverages6010008

66. Garcia, E.F., de Oliveira Araújo, A., Luciano, W.A., de Albuquerque, T.M.R., de Oliveira Arcanjo, N.M., Madruga, M.S., dos Santos Lima, M., Magnani, M., Saarela, M., de Souza, E.L. (2018). The performance of five fruit-derived and freeze-dried potentially probiotic Lactobacillus strains in apple, orange, and grape juices. Journal of the Science of Food and Agriculture, 98(13), 5000-5010. https://doi.org/10.1002/jsfa.9034

67. Garzón, A.G., Van de Velde, F., Drago, S.R. (2020). Gastrointestinal and colonic in vitro bioaccessibility of $\gamma$-aminobutiric acid (GABA) and phenolic compounds from novel fermented sorghum food. LWT - Food Science and Technology, 130, art. no. 109664 .

https://doi.org/10.1016/j.lwt.2020.109664

68. Gibbs, B.F., Zougman, A., Masse, R., Mulligan, C. (2004). Production and characterization of bioactive peptides from soy hydrolysate and soy-fermented food. Food Research International, 37(2), 123-131.

https://doi.org/10.1016/j.foodres.2003.09.010

69. Goodman R.E. (2020). AllergenOnline vesion 20.

http://www.allergenonline.org/

70. Guiné, R.P.F., Barroca, M.J., Coldea, T.E., Bartkiene, E., Anjos, O. (2021). Apple fermented products: an overview of technology, properties and health effects. Processes, 9(2), art. no. 223. https://doi.org/10.3390/pr9020223

71. Guldiken, B., Toydemir, G., Nur Memis, K., Okur, S., Boyacioglu, D., Capanoglu, E. (2016). Home-processed red beetroot (Beta vulgaris L.) products: changes in antioxidant properties and bioaccessibility. International Journal of Molecular Sciences, 17(6), art. no. 858 . https://doi.org/10.3390/ijms17060858

72. Gupta, S., Abu-Ghannam, N. (2011). Bioactive potential and possible health effects of edible brown seaweeds. Trends in Food Science and Technology, 22 (6), 315-326.

https://doi.org/10.1016/j.tifs.2011.03.011 
73. Gupta, S., Abu-Ghannam, N. (2012). Probiotic fermentation of plant based products: possibilities and opportunities. Critical Reviews in Food Science and Nutrition, 52 (2), 183-199. https://doi.org/10.1080/10408398.2010.499779

74. Habler, K., Hofer, K., Geißinger, C., Schüler, J., Hückelhoven, R., Hess, M., Gastl, M., Rychlik, M. (2016). Fate of Fusarium toxins during the malting process. Journal of Agricultural and Food Chemistry, 64(6), 1377-1384.

https://doi.org/10.1021/acs.jafc.5b05998

75. Hallmann, E., Kazimierczak, R., Marszałek, K., Drela, N., Kiernozek, E., Toomik, P., Matt, D., Luik, A., Rembiałkowska, E. (2017). The nutritive value of organic and conventional white cabbage (Brassica Oleracea L. Var. Capitata) and anti-apoptotic activity in gastric adenocarcinoma cells of sauerkraut juice produced therof. Journal of Agricultural and Food Chemistry, 65(37), 8171-8183.

https://doi.org/10.1021/acs.jafc.7b01078

76. Hermann, M. (2009). The impact of the European Novel Food Regulation on trade and food innovation based on traditional plant foods from developing countries. Food Policy, 34(6), 499-507. https://doi.org/10.1016/j.foodpol.2009.08.005

77. Hill, C., Guarner, F., Reid, G., Gibson, G.R., Merenstein, D.J., Pot, B., Morelli, L., Canani, R.B., Flint, H.J., Salminen, S., Calder, P.C., Sanders, M.E. (2014). The International Scientific Association for Probiotics and Prebiotics consensus statement on the scope and appropriate use of the term probiotic. Nature Reviews Gastroenterology \& Hepatology, 11 (8), 506-514. https://doi.org/10.1038/nrgastro.2014.66

78. Hu, Y., Li, Y., Liu, X. (2020). Soybean peptides promote yoghurt fermentation and quality. Biotechnology Letters, 42(10), 1927-1937.

https://doi.org/10.1007/s10529-020-02912-2

79. Huang, F., Hong, R., Zhang, R., Dong, L., Bai, Y., Liu, L., Jia, X., Wang, G., Zhang, M. (2019). Dynamic variation in biochemical properties and prebiotic activities of polysaccharides from longan pulp during fermentation process. International Journal of Biological Macromolecules, 132, 915-921.

https://doi.org/10.1016/j.ijbiomac.2019.04.032

80. Huang, X., Schuppan, D., Rojas Tovar, L.E., Zevallos, V.F., Loponen, J., Gänzle, M. (2020). Sourdough fermentation degrades wheat alpha-amylase/trypsin inhibitor (ATI) and reduces pro-inflammatory activity. Foods (Basel, Switzerland), 9(7), art. no. 943 .

https://doi.org/10.3390/foods9070943

81. Hubert, J., Berger, M., Nepveu, F., Paul, F., Daydé, J. (2008). Effects of fermentation on the phytochemical composition and antioxidant properties of soy germ. Food Chemistry, 109(4), 709-721.

https://doi.org/10.1016/j.foodchem.2007.12.081

82. Hussain, M.A., Knight, M.I., Britz, M.L. (2009). Proteomic analysis of lactose-starved Lactobacillus casei during stationary growth phase. Journal of Applied Microbiology, 106(3), 764-773. https://doi.org/10.1111/j.1365-2672.2008.03961.x

83. Inomata, N., Miyakawa, M., Aihara, M. (2018). Surfing as a risk factor for sensitization to poly ( $\gamma$-glutamic acid) in fermented soybeans, natto, allergy. Allergology International, 67(3), 341-346. https://doi.org/10.1016/j.alit.2017.11.001
84. Isas, A.S., Mariotti Celis, M.S., Pérez Correa, J.R., Fuentes, E., Rodríguez, L., Palomo, I., Mozzi, F., Van Nieuwenhove, C. (2020). Functional fermented cherimoya (Annona cherimola Mill.) juice using autochthonous lactic acid bacteria. Food Research International, 138, art. no. 109729.

https://doi.org/10.1016/j.foodres.2020.109729

85. Jakubczyk, A., Karaś, M., Złotek, U., Szymanowska, U. (2017). Identification of potential inhibitory peptides of enzymes involved in the metabolic syndrome obtained by simulated gastrointestinal digestion of fermented bean (Phaseolus vulgaris L.) seeds. Food Research International, 100, 489-496.

https://doi.org/10.1016/j.foodres.2017.07.046

86. Jung, W.Y., Jung, J.Y., Lee, H.J., Jeon, C.O. (2016). Functional characterization of bacterial communities responsible for fermentation of doenjang: a traditional korean fermented soybean paste. Frontiers in Microbiology, 7, art. no. 827.

https://doi.org/10.3389/fmicb.2016.00827

87. Juodeikiene, G., Bartkiene, E., Cernauskas, D., Cizeikiene, D., Zadeike, D., Lele, V., Bartkevics, V. (2018). Antifungal activity of lactic acid bacteria and their application for Fusarium mycotoxin reduction in malting wheat grains. $L W T$ - Food Science and Technology, 89, 307-314.

https://doi.org/10.1016/j.lwt.2017.10.061

88. Kapusta-Duch, J., Kusznierewicz, B., Leszczyńska, T., Borczak, B. (2017). Effect of package type on selected parameters of nutritional quality of chill-stored white sauerkraut. Polish Journal of Food and Nutrition Sciences, 67(2), 137-144. https://doi.org/10.1515/pjfns-2016-0014

89. Khan, I., Kang, S.C. (2017). Apoptotic activity of Lactobacillus plantarum DGK-17-fermented soybean seed extract in human colon cancer cells via ROS-JNK signaling pathway. Journal of Food Science, 82 (6), 1475-1483.

https://doi.org/10.1111/1750-3841.13732

90. Kheterpaul, N., Chauhan, B.M. (1991). Effect of natural fermentation on phytate and polyphenolic content and in-vitro digestibility of starch and protein of pearl millet (Pennisetum typhoideum). Journal of the Science of Food and Agriculture, 55(2), 189-195.

https://doi.org/10.1002/jsfa.2740550204

91. Klewicka, E., Czyżowska, A. (2011). Biological stability of lactofermented beetroot juice during refrigerated storage. Polish Journal of Food and Nutrition Sciences, 61 (4), 251-256.

https://doi.org/10.2478/v10222-011-0028-2

92. Kun, S., Rezessy-Szabó, J.M., Nguyen, Q.D., Hoschke, Á. (2008). Changes of microbial population and some components in carrot juice during fermentation with selected Bifidobacterium strains. Process Biochemistry, 43(8), 816-821. https://doi.org/10.1016/j.procbio.2008.03.008

93. Kwaw, E., Ma, Y., Tchabo, W., Apaliya, M.T., Wu, M., Sackey, A.S., Xiao, L., Tahir, H.E. (2018). Effect of Lactobacillus strains on phenolic profile, color attributes and antioxidant activities of lactic-acid-fermented mulberry juice. Food Chemistry, 250, $148-154$.

https://doi.org/10.1016/j.foodchem.2018.01.009

94. Kwon, Y.S., Lee, S., Lee, S.H., Kim, H.J., Lee, C.H. (2019). Comparative evaluation of six traditional fermented soybean products in east asia: a metabolomics approach. Metabolites, 9(9), art. no. 183.

https://doi.org/10.3390/metabo9090183 
95. Laatikainen, R., Koskenpato, J., Hongisto, S.-M., Loponen, J., Poussa, T., Hillilä, M., Korpela, R. (2016). Randomised clinical trial: low-FODMAP rye bread vs. regular rye bread to relieve the symptoms of irritable bowel syndrome. Alimentary Pharmacology \& Therapeutics, 44(5), 460-470.

https://doi.org/10.1111/apt.13726

96. Laatikainen, R., Koskenpato, J., Hongisto, S.-M., Loponen, J., Poussa, T., Huang, X., Sontag-Strohm, T., Salmenkari, H., Korpela, R. (2017). Pilot study: comparison of sourdough wheat bread and yeast-fermented wheat bread in individuals with wheat sensitivity and irritable bowel syndrome. Nutrients, $9(11)$, art. no. 1215.

https://doi.org/10.3390/nu9111215

97. Ladero, V., Coton, M., Fernández, M., Buron, N., Martín, M.C., Guichard, H., Coton, E., Alvarez, M.A. (2011). Biogenic amines content in Spanish and French natural ciders: Application of qPCR for quantitative detection of biogenic amine-producers. Food Microbiology, 28(3), 554-561.

https://doi.org/10.1016/j.fm.2010.11.005

98. Lee, J.H., Kim, B., Hwang, C.E., Haque, M.A., Kim, S.C., Lee, C.S., Kang, S.S., Cho, K.M., Lee, D.H. (2018). Changes in conjugated linoleic acid and isoflavone contents from fermented soymilks using Lactobacillus plantarum P1201 and screening for their digestive enzyme inhibition and antioxidant properties. Journal of Functional Foods, 43, 17-28. https://doi.org/10.1016/j.jff.2018.01.022

99. Lee, S.M., Lee, J.Y., Cho, Y.J., Kim, M.S., Kim, Y.-S. (2018). Determination of volatiles and carotenoid degradation compounds in red pepper fermented by Lactobacillus parabuchneri. Journal of Food Science, 83(8), 2083-2091.

https://doi.org/10.1111/1750-3841.14221

100. Lee, W., Ahn, G., Lee, B.-J., Wijesinghe, W.A.J.P., Kim, D., Yang, H., Kim, Y.M., Park, S.J., Jee, Y., Jeon, Y.-J. (2013). Radio-protective effect of polysaccharides isolated from $\mathrm{Lac}$ tobacillus brevis-fermented Ecklonia cava. International Journal of Biological Macromolecules, 52, 260-266. https://doi.org/10.1016/j.ijbiomac.2012.10.004

101. Lee, Y.-C., Kung, H.-F., Huang, Y.-L., Wu, C.-H., Huang, Y.R., Tsai, Y.-H. (2016). Reduction of biogenic amines during miso fermentation by Lactobacillus plantarum as a starter culture. Journal of Food Protection, 79(9), 1556-1561. https://doi.org/10.4315/0362-028X.JFP-16-060

102. Li, C., Li, W., Chen, X., Feng, M., Rui, X., Jiang, M., Dong, M. (2014). Microbiological, physicochemical and rheological properties of fermented soymilk produced with exopolysaccharide (EPS) producing lactic acid bacteria strains. $L W T-$ Food Science and Technology, 57(2), 477-485. https://doi.org/10.1016/j.lwt.2014.02.025

103. Liang, J., Han, B.-Z., Nout, M.J.R., Hamer, R.J. (2008). Effects of soaking, germination and fermentation on phytic acid, total and in vitro soluble zinc in brown rice. Food Chemistry, 110(4), 821-828.

https://doi.org/10.1016/j.foodchem.2008.02.064

104. Licandro, H., Ho, P.H., Nguyen, T.K.C., Petchkongkaew, A., Nguyen, H. Van, Chu-Ky, S., Nguyen, T.V.A., Lorn, D., Waché, Y. (2020). How fermentation by lactic acid bacteria can address safety issues in legumes food products? Food Control, 110, art. no. 106957.

https://doi.org/10.1016/j.foodcont.2019.106957
105. Limón, R.I., Peñas, E., Torino, M.I., Martínez-Villaluenga, C., Dueñas, M., Frias, J. (2015). Fermentation enhances the content of bioactive compounds in kidney bean extracts. Food Chemistry, 172, 343-352. https://doi.org/10.1016/j.foodchem.2014.09.084

106. Liu, J., Zhou, J., Wang, L., Ma, Z., Zhao, G., Ge, Z., Zhu, H., Qiao, J. (2017). Improving nitrogen source utilization from defatted soybean meal for nisin production by enhancing proteolytic function of Lactococcus lactis F44. Scientific Reports, 7(1), art. no. 6189 .

https://doi.org/10.1038/s41598-017-06537-w

107. Mæhre, H.K., Malde, M.K., Eilertsen, K.E., Elvevoll, E.O. (2014). Characterization of protein, lipid and mineral contents in common Norwegian seaweeds and evaluation of their potential as food and feed. Journal of the Science of Food and Agriculture, 94(15), 3281-3290.

https://doi.org/10.1002/jsfa.6681

108. Magishi, N., Yuikawa, N., Kobayashi, M., Taniuchi, S. (2017). Degradation and removal of soybean allergen in Japanese soy sauce. Molecular Medicine Reports, 16(2), 2264-2268. https://doi.org/10.3892/mmr.2017.6815

109. Mah, J.-H., Park, Y.K., Jin, Y.H., Lee, J.-H., Hwang, H.-J. (2019). Bacterial production and control of biogenic amines in Asian fermented soybean foods. Foods (Basel, Switzerland), $8(2)$, art. no. 85 .

https://doi.org/10.3390/foods8020085

110. Marco, M.L., Heeney, D., Binda, S., Cifelli, C.J., Cotter, P.D., Foligné, B., Gänzle, M., Kort, R., Pasin, G., Pihlanto, A., Smid, E.J., Hutkins, R. (2017). Health benefits of fermented foods: microbiota and beyond. Current Opinion in Biotechnology, 44, 94-102.

https://doi.org/10.1016/j.copbio.2016.11.010

111. María Landete, J., Hernández, T., Robredo, S., Dueñas, M., de las Rivas, B., Estrella, I., Muñoz, R. (2015). Effect of soaking and fermentation on content of phenolic compounds of soybean (Glycine max cv. Merit) and mung beans (Vigna radiata [L] Wilczek). International Journal of Food Sciences and Nutrition, 66(2), 203-209.

https://doi.org/10.3109/09637486.2014.986068

112. Markkinen, N., Laaksonen, O., Nahku, R., Kuldjärv, R., Yang, B. (2019). Impact of lactic acid fermentation on acids, sugars, and phenolic compounds in black chokeberry and sea buckthorn juices. Food Chemistry, 286, 204-215. https://doi.org/10.1016/j.foodchem.2019.01.189

113. Martinez-Villaluenga, C., Peñas, E., Frias, J., Ciska, E., Honke, J., Piskula, M.K., Kozlowska, H., Vidal-Valverde, C. (2009). Influence of fermentation conditions on glucosinolates, ascorbigen, and ascorbic acid content in white cabbage (Brassica oleracea var. capitata cv. Taler) cultivated in different seasons. Journal of Food Science, 74(1), C62-C67. https://doi.org/10.1111/j.1750-3841.2008.01017.x

114. Martins, E.M.F., Ramos, A.M., Vanzela, E.S.L., Stringheta, P.C., de Oliveira Pinto, C.L., Martins, J.M. (2013). Products of vegetable origin: A new alternative for the consumption of probiotic bacteria. Food Research International, 51(2), 764-770.

https://doi.org/10.1016/j.foodres.2013.01.047

115. Matejčeková, Z., Mikulajová, A., Vlková, E., Liptáková, D., Mošovská, S., Hybenová, E., Valík, L. (2019). Design of bacte- 
rial cultures in fermented functional maize product formulation. Polish Journal of Food and Nutrition Sciences, 69(4), 417-426. https://doi.org/10.31883/pjfns/112642

116. Meléndez-Martínez, A.J. (2019). An overview of carotenoids, apocarotenoids, and vitamin A in agro-food, nutrition, health, and disease. Molecular Nutrition \& Food Research, 63(15), art. no. 1801045 .

https://doi.org/10.1002/mnfr.201801045

117. Mihhalevski, A., Nisamedtinov, I., Hälvin, K., Ošeka, A., Paalme, T. (2013). Stability of B-complex vitamins and dietary fiber during rye sourdough bread production. Journal of Cereal Science, 57(1), 30-38.

https://doi.org/10.1016/j.jcs.2012.09.007

118. Minervini, F., De Angelis, M., Di Cagno, R., Gobbetti, M. (2014). Ecological parameters influencing microbial diversity and stability of traditional sourdough. International Journal of Food Microbiology, 171, 136-146.

https://doi.org/10.1016/j.ijfoodmicro.2013.11.021

119. Mo, H., Kariluoto, S., Piironen, V., Zhu, Y., Sanders, M.G., Vincken, J.-P., Wolkers-Rooijackers, J., Nout, M.J.R. (2013). Effect of soybean processing on content and bioaccessibility of folate, vitamin B12 and isoflavones in tofu and tempe. Food Chemistry, 141(3), 2418-2425.

https://doi.org/10.1016/j.foodchem.2013.05.017

120. Moon, S.H., Kim, C.R., Chang, H.C. (2018). Heterofermentative lactic acid bacteria as a starter culture to control kimchi fermentation. LWT - Food Science and Technology, 88, 181-188. https://doi.org/10.1016/j.Iwt.2017.10.009

121. Mullaney, J.A., Kelly, W.J., McGhie, T.K., Ansell, J., Heyes, J.A. (2013). Lactic acid bacteria convert glucosinolates to nitriles efficiently yet differently from Enterobacteriaceae. Journal of Agricultural and Food Chemistry, 61 (12), 3039-3046.

https://doi.org/10.1021/jf305442

122. Mustafa, S.M., Chua, L.S., El-Enshasy, H.A. (2019). Effects of agitation speed and kinetic studies on probiotication of pomegranate juice with Lactobacillus casei. Molecules (Basel, Switzerland), 24(13), art. no. 2357. https://doi.org/10.3390/molecules24132357

123. Nachi, I., Fhoula, I., Smida, I., Ben Taher, I., Chouaibi, M., Jaunbergs, J., Bartkevics, V., Hassouna, M. (2018). Assessment of lactic acid bacteria application for the reduction of acrylamide formation in bread. LWT - Food Science and Technology, $92,435-441$.

https://doi.org/10.1016/j.Iwt.2018.02.061

124. Nasiri E.B., Kadivar, M., Shahedi, M., Soleimanian-Zad, S. (2017). Reduction of acrylamide in whole-wheat bread by combining lactobacilli and yeast fermentation. Food Additives \& Contaminants: Part A, 34(11), 1904-1914. https://doi.org/10.1080/19440049.2017.1378444

125. Nawaz, K.A.A., David, S.M., Murugesh, E., Thandeeswaran, M., Kiran, K.G., Mahendran, R., Palaniswamy, M., Angayarkanni, J. (2017). Identification and in silico characterization of a novel peptide inhibitor of angiotensin converting enzyme from pigeon pea (Cajanus cajan). Phytomedicine, 36, 1-7. https://doi.org/10.1016/j.phymed.2017.09.013

126. Nguyen, T.T.T., Loiseau, G., Icard-Vernière, C., Rochette, I., Trèche, S., Guyot, J.-P. (2007). Effect of fermentation by amylolytic lactic acid bacteria, in process combinations, on characteristics of rice/soybean slurries: A new method for preparing high energy density complementary foods for young children. Food Chemistry, 100(2), 623-631.

https://doi.org/10.1016/j.foodchem.2005.09.080

127. Oloo, B.O., Shitandi, A., Mahungu, S., Malinga, J.B., Rose, O.B. (2014). Effects of lactic acid fermentation on the retention of beta-carotene content in orange fleshed sweet potatoes. International Journal of Food Studies, 3(1), 13-33.

https://doi.org/10.7455/ijfs/3.1.2014.a2

128. Omoba, O.S., Isah, L.R. (2018). Influence of sourdough fermentation on amino acids composition, phenolic profile, and antioxidant properties of sorghum biscuits. Preventive $\mathrm{Nu}$ trition and Food Science, 23(3), 220-227. https://doi.org/10.3746/pnf.2018.23.3.220

129. Palani, K., Harbaum-Piayda, B., Meske, D., Keppler, J.K., Bockelmann, W., Heller, K.J., Schwarz, K. (2016). Influence of fermentation on glucosinolates and glucobrassicin degradation products in sauerkraut. Food Chemistry, 190, 755-762. https://doi.org/10.1016/j.foodchem.2015.06.012

130. Palla, M., Cristani, C., Giovannetti, M., Agnolucci, M. (2017). Identification and characterization of lactic acid bacteria and yeasts of PDO Tuscan bread sourdough by culture dependent and independent methods. International Journal of Food Microbiology, 250, 19-26. https://doi.org/10.1016/j.ijfoodmicro.2017.03.015

131. Pan, R., Xu, T., Bai, J., Xia, S., Liu, Q., Li, J., Xiao, X., Dong, Y. (2020). Effect of Lactobacillus plantarum fermented barley on plasma glycolipids and insulin sensitivity in subjects with metabolic syndrome. Journal of Food Biochemistry, 44(11), art. no. e13471. https://doi.org/10.1111/jfbc.13471

132. Paramithiotis, S., Doulgeraki, A.I., Tsilikidis, I., Nychas, G.-J.E., Drosinos, E.H. (2012). Fate of Listeria monocytogenes and Salmonella Typhimurium during spontaneous cauliflower fermentation. Food Control, 27(1), 178-183.

https://doi.org/10.1016/j.foodcont.2012.03.022

133. Pejcz, E., Czaja, A., Wojciechowicz-Budzisz, A., Gil, Z., Spychaj, R. (2017). The potential of naked barley sourdough to improve the quality and dietary fibre content of barley enriched wheat bread. Journal of Cereal Science, 77, 97-101.

https://doi.org/10.1016/j.jcs.2017.08.007

134. Pejcz, E., Spychaj, R., Gil, Z. (2020). Technological methods for reducing the content of fructan in rye bread. European Food Research and Technology, 246(9), 1839-1846. https://doi.org/10.1007/s00217-020-03537-5

135. Pepper, S.J., Britz, M.L. (2019). An acid up-regulated surface protein of Lactobacillus paracasei Strain GCRL 46 is phylogenetically related to the secreted glucan- (gpbb) and immunoglobulin-binding (siba) protein of pathogenic streptococci. International Journal of Molecular Sciences, 20(7), art. no. 1610. https://doi.org/10.3390/ijms20071610

136. Pereira, H.S., Leão-Ferreira, L.R., Moussatché, N., Teixeira, V.L., Cavalcanti, D.N., Costa, L.J., Diaz, R., Frugulhetti, I.C.P.P. (2004). Antiviral activity of diterpenes isolated from the Brazilian marine alga Dictyota menstrualis against human immunodeficiency virus type 1 (HIV-1). Antiviral Research, 64(1), 69-76. https://doi.org/10.1016/j.antiviral.2004.06.006

137. Pereira, L., Critchley, A.T. (2020). The COVID 19 novel coronavirus pandemic 2020: seaweeds to the rescue? Why does substantial, supporting research about the antiviral properties of seaweed polysaccharides seem to go unrecognized 
by the pharmaceutical community in these desperate times? Journal of Applied Phycology, 32(3), 1875-1877. https://doi.org/10.1007/s10811-020-02143-y

138. Petkova, M., Stefanova, P., Gotcheva, V., Kuzmanova, I., Angelov, A. (2020). Microbiological and physicochemical characterization of traditional Bulgarian sourdoughs and screening of lactic acid bacteria for amylolytic activity. Journal of Chemical Technology and Metallurgy, 55(5), 921-934.

139. Pistarino, E., Aliakbarian, B., Casazza, A.A., Paini, M., Cosulich, M.E., Perego, P. (2013). Combined effect of starter culture and temperature on phenolic compounds during fermentation of Taggiasca black olives. Food Chemistry, 138(2-3), 2043-2049. https://doi.org/10.1016/j.foodchem.2012.11.021

140. Quirante-Moya, S., García-Ibañez, P., Quirante-Moya, F., Villaño, D., Moreno, D.A. (2020). The role of brassica bioactives on human health: are we studying it the right way? Molecules (Basel, Switzerland), 25(7), art. no. 1591. https://doi.org/10.3390/molecules25071591

141. Ramnani, P., Chitarrari, R., Tuohy, K., Grant, J., Hotchkiss, S., Philp, K., Campbell, R., Gill, C., Rowland, I. (2012). In vitro fermentation and prebiotic potential of novel low molecular weight polysaccharides derived from agar and alginate seaweeds. Anaerobe, 18(1), 1-6.

https://doi.org/10.1016/j.anaerobe.2011.08.003

142. Rathore, S., Salmerón, I., Pandiella, S.S. (2012). Production of potentially probiotic beverages using single and mixed cereal substrates fermented with lactic acid bacteria cultures. Food Microbiology, 30(1), 239-244.

https://doi.org/10.1016/j.fm.2011.09.001

143. Rekha, C.R., Vijayalakshmi, G. (2010). Bioconversion of isoflavone glycosides to aglycones, mineral bioavailability and vitamin B complex in fermented soymilk by probiotic bacteria and yeast. Journal of Applied Microbiology, 109(4), 1198-1208. https://doi.org/10.1111/j.1365-2672.2010.04745.x

144. Rianingsih, L., Sumardianto (2020). Antioxidant activity in seaweed (Sargassum sp.) extract fermented with Lactobacillus plantarum and Lactobacillus acidophilus. Earth and Environmental Science, 530, art. no. 012011.

https://doi.org/10.1088/1755-1315/530/1/012011

145. Ricci, A., Cirlini, M., Calani, L., Bernini, V., Neviani, E., Del Rio, D., Galaverna, G., Lazzi, C. (2019). In vitro metabolism of elderberry juice polyphenols by lactic acid bacteria. Food Chemistry, 276, 692-699. https://doi.org/10.1016/j.foodchem.2018.10.046

146. Rodríguez-Jasso, R.M., Mussatto, S.I., Sepúlveda, L., Agrasar, A.T., Pastrana, L., Aguilar, C.N., Teixeira, J.A. (2013). Fungal fucoidanase production by solid-state fermentation in a rotating drum bioreactor using algal biomass as substrate. Food and Bioproducts Processing, 91 (4), 587-594. https://doi.org/10.1016/j.fbp.2013.02.004

147. Salmerón, I., Thomas, K., Pandiella, S.S. (2015). Effect of potentially probiotic lactic acid bacteria on the physicochemical composition and acceptance of fermented cereal beverages. Journal of Functional Foods, 15, 106-115. https://doi.org/10.1016/j.jff.2015.03.012

148. Samtiya, M., Aluko, R.E., Dhewa, T. (2020). Plant food antinutritional factors and their reduction strategies: an overview. Food Production, Processing and Nutrition, 2(1), art. no. 6. https://doi.org/10.1186/s43014-020-0020-5
149. Sanjukta, S., Rai, A.K. (2016). Production of bioactive peptides during soybean fermentation and their potential health benefit. Trends in Food Science \& Technology, 50, 1-10. hhttps://doi.org/10.1016/j.tifs.2016.01.010

150. Santamaría, L., Reverón, I., de Felipe, F.L., de las Rivas, B., Muñoz, R. (2018). Ethylphenol formation by Lactobacillus plantarum: Identification of the enzyme involved in the reduction of vinylphenols. Applied and Environmental Microbiology, 84(17), art. no. e01064-18. https://doi.org/10.1128/AEM.01064-18

151. Santamaría, L., Reverón, I., López de Felipe, F., de las Rivas, B., Muñoz, R. (2018). Unravelling the reduction pathway as an alternative metabolic route to hydroxycinnamate decarboxylation in Lactobacillus plantarum. Applied and Environmental Microbiology, 84(15), art. no. e01123-18.

https://doi.org/10.1128/AEM.01123-18

152. Santos, C.C.A. do A., Libeck, B. da S., Schwan, R.F. (2014). Co-culture fermentation of peanut-soy milk for the development of a novel functional beverage. International Journal of Food Microbiology, 186, 32-41.

https://doi.org/10.1016/j.ijfoodmicro.2014.06.011

153. Seo, H.S., Lee, S., Singh, D., Shin, H.W., Cho, S.A., Lee, C.H. (2018). Untargeted metabolite profiling for koji-fermentative bioprocess unravels the effects of varying substrate types and microbial inocula. Food Chemistry, 266, 161-169. https://doi.org/10.1016/j.foodchem.2018.05.048

154. Shobharani, P., Halami, P.M., Sachindra, N.M. (2013). Potential of marine lactic acid bacteria to ferment Sargassum sp. for enhanced anticoagulant and antioxidant properties. Journal of Applied Microbiology, 114(1), 96-107.

https://doi.org/10.1111/jam.12023

155. Singh, R.S., Thakur, S.R., Bansal, P. (2015). Algal lectins as promising biomolecules for biomedical research. Critical Reviews in Microbiology, 41 (1), 77-88.

hhttps://doi.org/10.3109/1040841X.2013.798780

156. Song, J.L., Choi, J.H., Seo, J.H., Lim, Y.I., Park, K.Y. (2014). Anti-colitic effects of kanjangs (fermented soy sauce and sesame sauce) in dextran sulfate sodium-induced colitis in mice. Journal of Medicinal Food, 17(9), 1027-1035.

https://doi.org/10.1089/jmf.2013.3119

157. Soundararajan, P., Kim, J.S. (2018). Anti-carcinogenic glucosinolates in cruciferous vegetables and their antagonistic effects on prevention of cancers. Molecules, 23(11), art. no. 2983. https://doi.org/10.3390/molecules23112983

158. Spaggiari, M., Ricci, A., Calani, L., Bresciani, L., Neviani, E., Dall'Asta, C., Lazzi, C., Galaverna, G. (2020). Solid state lactic acid fermentation: A strategy to improve wheat bran functionality. LWT - Food Science and Technology, 118, art. no. 108668. https://doi.org/10.1016/j.lwt.2019.108668

159. Starzyńska-Janiszewska, A., Stodolak, B. (2011). Effect of inoculated lactic acid fermentation on antinutritional and antiradical properties of grass pea (Lathyrus sativus 'Krab') flour. Polish Journal of Food and Nutrition Sciences, 61 (4), 245-249. https://doi.org/10.2478/v10222-011-0027-3

160. Stefańska, I., Piasecka-Jóźwiak, K., Kotyrba, D., Kolenda, M., Stecka, K.M. (2016). Selection of lactic acid bacteria strains for the hydrolysis of allergenic proteins of wheat flour. Journal of the Science of Food and Agriculture, 96(11), 3897-3905. https://doi.org/10.1002/jsfa.7588 
161. Su, L.-W., Cheng, Y.-H., Hsiao, F.S.-H., Han, J.-C., Yu, Y.-H. (2018). Optimization of mixed solid-state fermentation of soybean meal by Lactobacillus species and Clostridium butyricum. Polish Journal of Microbiology, 67(3), 297-305. https://doi.org/10.21307/pjm-2018-035

162. Tabaszewska, M., Gabor, A., Jaworska, G., Drożdż, I. (2018). Effect of fermentation and storage on the nutritional value and contents of biologically-active compounds in lacto-fermented white asparagus (Asparagus officinalis L.). LWT - Food Science and Technology, 92, 67-72. https://doi.org/10.1016/j.Iwt.2018.02.003

163. Thomas, I., Siew, L.Q.C., Watts, T.J., Haque, R. (2019). Seaweed allergy. Journal of Allergy and Clinical Immunology: In Practice, 7(2), 714-715. https://doi.org/10.1016/j.jaip.2018.11.009

164. Toi, M., Hirota, S., Tomotaki, A., Sato, N., Hozumi, Y., Anan, K., Nagashima, T., Tokuda, Y., Masuda, N., Ohsumi, S., Ohno, S., Takahashi, M., Hayashi, H., Yamamoto, S., Ohashi, Y. (2013). Probiotic beverage with soy isoflavone consumption for breast cancer prevention: a case-control study. Current Nutrition and Food Science, 9(3), 194-200.

https://doi.org/10.2174/15734013113099990001

165. Toktaş, B., Bildik, F., Özçelik, B. (2018). Effect of fermentation on anthocyanin stability and in vitro bioaccessibility during shalgam (şalgam) beverage production. Journal of the Science of Food and Agriculture, 98(8), 3066-3075. https://doi.org/10.1002/jsfa.8806

166. Tong, L.-T., Zhong, K., Liu, L., Zhou, X., Qiu, J., Zhou, S. (2015). Effects of dietary hull-less barley $\beta$-glucan on the cholesterol metabolism of hypercholesterolemic hamsters. Food Chemistry, 169, 344-349. https://doi.org/10.1016/j.foodchem.2014.07.157

167. Torres-Pitarch, A., Gardiner, G.E., Cormican, P., Rea, M., Crispie, F., O’Doherty, J.V., Cozannet, P., Ryan, T., Cullen, J., Lawlor, P.G. (2020). Effect of cereal fermentation and carbohydrase supplementation on growth, nutrient digestibility and intestinal microbiota in liquid-fed grow-finishing pigs. Scientific Reports, 10(1), art. no. 13716.

https://doi.org/10.1038/s41598-020-70443-x

168. Unlu, N.Z., Bohn, T., Francis, D.M., Nagaraja, H.N., Clinton, S.K., Schwartz, S.J. (2007). Lycopene from heat-induced cis-isomer-rich tomato sauce is more bioavailable than from all-trans-rich tomato sauce in human subjects. British Journal of Nutrition, 98(1), 140-146.

https://doi.org/10.1017/S0007114507685201

169. Uyttendaele, M., Jaykus, L.-A., Amoah, P., Chiodini, A., Cunliffe, D., Jacxsens, L., Holvoet, K., Korsten, L., Lau, M., McClure, P., Medema, G., Sampers, I., Rao Jasti, P. (2015). Microbial hazards in irrigation water: standards, norms, and testing to manage use of water in fresh produce primary production. Comprehensive Reviews in Food Science and Food Safety, 14(4), 336-356.

https://doi.org/10.1111/1541-4337.12133

170. Van Beeck, W., Verschueren, C., Wuyts, S., van den Broek, M.F.L., Uyttendaele, M., Lebeer, S. (2020). Robustness of fermented carrot juice against Listeria monocytogenes, Salmonella Typhimurium and Escherichia coli O157:H7. International Journal of Food Microbiology, 335, art. no. 108854.

https://doi.org/10.1016/j.ijfoodmicro.2020.108854
171. Vasiee, A., Falah, F., Behbahani, B.A., Tabatabaee-Yazdi, F. (2020). Probiotic characterization of Pediococcus strains isolated from Iranian cereal-dairy fermented product: Interaction with pathogenic bacteria and the enteric cell line Caco-2. Journal of Bioscience and Bioengineering, 130(5), 471-479.

https://doi.org/10.1016/j.jbiosc.2020.07.002

172. Vauzour, D., Rodriguez-Mateos, A., Corona, G., Oruna-Concha, M.J., Spencer, J.P.E. (2010). Polyphenols and human health: prevention of disease and mechanisms of action. Nutrients, 2(11), 1106-1131.

https://doi.org/10.3390/nu2111106

173. Verni, M., Demarinis, C., Rizzello, C.G., Baruzzi, F. (2020). Design and characterization of a novel fermented beverage from lentil grains. Foods, 9(7), art. no. 893.

https://doi.org/10.3390/foods9070893

174. Verni, M., Rizzello, C.G., Coda, R. (2019). Fermentation biotechnology applied to cereal industry by-products: nutritional and functional insights. Frontiers in Nutrition, (6), art. no. 42. https://doi.org/10.3389/fnut.2019.00042

175. Verón, H.E., Gauffin Cano, P., Fabersani, E., Sanz, Y., Isla, M.I., Fernández Espinar, M.T., Gil Ponce, J.V., Torres, S. (2019). Cactus pear (Opuntia ficus-indica) juice fermented with autochthonous Lactobacillus plantarum S-811. Food \& Function, 10(2), 1085-1097.

https://doi.org/10.1039/C8F001591K

176. Wacoo, A.P., Mukisa, I.M., Meeme, R., Byakika, S., Wendiro, D., Sybesma, W., Kort, R. (2019). Probiotic enrichment and reduction of aflatoxins in a traditional African maize-based fermented food. Nutrients, 11 (2), art. no. 265.

https://doi.org/10.3390/nu11020265

177. Wang, J., Zhao, X., Tian, Z., He, C., Yang, Y., Yang, Z. (2015). Isolation and characterization of exopolysaccharide-producing Lactobacillus plantarum SKT109 from Tibet Kefir. Polish Journal of Food and Nutrition Sciences, 65(4), 269-279.

https://doi.org/10.1515/pjfns-2015-0023

178. Wiczkowski, W., Szawara-Nowak, D., Romaszko, J. (2016). The impact of red cabbage fermentation on bioavailability of anthocyanins and antioxidant capacity of human plasma. Food Chemistry, 190, 730-740.

https://doi.org/10.1016/j.foodchem.2015.06.021

179. Wiczkowski, W., Szawara-Nowak, D., Topolska, J. (2015). Changes in the content and composition of anthocyanins in red cabbage and its antioxidant capacity during fermentation, storage and stewing. Food Chemistry, 167, 115-123. https://doi.org/10.1016/j.foodchem.2014.06.087

180. Wronkowska, M., Jeliński, T., Majkowska, A., Zieliński, H. (2018). Physical properties of buckwheat water biscuits formulated from fermented flours by selected lactic acid bacteria. Polish Journal of Food and Nutrition Sciences, 68(1), 25-31. https://doi.org/10.1515/pjfns-2017-0027

181. Xia, J., Zu, Q., Yang, A., Wu, Z., Li, X., Tong, P., Yuan, J., Wu, Y., Fan, Q., Chen, H. (2019). Allergenicity reduction and rheology property of Lactobacillus-fermented soymilk. Journal of the Science of Food and Agriculture, 99(15), 6841-6849. https://doi.org/10.1002/jsfa.9969

182. Xiao, X., Tan, C., Sun, X., Zhao, Y., Zhang, J., Zhu, Y., Bai, J., Dong, Y., Zhou, X. (2020). Effects of fermentation on structural characteristics and in vitro physiological activities of barley $\beta$-glucan. Carbohydrate Polymers, 231, art. no. 115685. https://doi.org/10.1016/j.carbpol.2019.115685 
183. Xiao, Y., Zhang, S., Tong, H., Shi, S. (2018). Comprehensive evaluation of the role of soy and isoflavone supplementation in humans and animals over the past two decades. Phytotherapy Research, 32(3), 384-394. https://doi.org/10.1002/ptr.5966

184. Xu, Y., Coda, R., Shi, Q., Tuomainen, P., Katina, K., Tenkanen, M. (2017). Exopolysaccharides production during the fermentation of soybean and fava bean flours by Leuconostoc mesenteroides DSM 20343. Journal of Agricultural and Food Chemistry, 65(13), 2805-2815.

https://doi.org/10.1021/acs.jafc.6b05495

185. Xu, Y., Zhou, T., Tang, H., Li, X., Chen, Y., Zhang, L., Zhang, J. (2020). Probiotic potential and amylolytic properties of lactic acid bacteria isolated from Chinese fermented cereal foods. Food Control, 111, art. no. 107057.

https://doi.org/10.1016/j.foodcont.2019.107057

186. Yagmur, G., Tanguler, H., Leventdurur, S., Elmaci, S.B., Turhan, E.U., Francesca, N., Settanni, L., Moschetti, G., Erten, H. (2016). Identification of predominant lactic acid bacteria and yeasts of turkish sourdoughs and selection of starter cultures for liquid sourdough production using different flours and dough yields. Polish Journal of Food and Nutrition Sciences, 66(2), 99-107.

https://doi.org/10.1515/pjfns-2015-0041

187. Yang, A., Zuo, L., Cheng, Y., Wu, Z., Li, X., Tong, P., Chen, H. (2018). Degradation of major allergens and allergenicity reduction of soybean meal through solid-state fermentation with microorganisms. Food and Function, 9(3), 1899-1909. https://doi.org/10.1039/C7FO01824J

188. Yang, J., Ji, Y., Park, H., Lee, J., Park, S., Yeo, S., Shin, H., Holzapfel, W.H. (2014). Selection of functional lactic acid bacteria as starter cultures for the fermentation of Korean leek (Allium tuberosum Rottler ex Sprengel.). International Journal of Food Microbiology, 191, 164-171. https://doi.org/10.1016/j.ijfoodmicro.2014.09.016

189. Ye, J.-H., Huang, L.-Y., Terefe, N.S., Augustin, M.A. (2019). Fermentation-based biotransformation of glucosinolates, phenolics and sugars in retorted broccoli puree by lactic acid bacteria. Food Chemistry, 286, 616-623.

https://doi.org/10.1016/j.foodchem.2019.02.030

190. Zadeike, D., Vaitkeviciene, R., Bartkevics, V., Bogdanova, E., Bartkiene, E., Lele, V., Juodeikiene, G., Cernauskas, D., Valatkeviciene, Z. (2021). The expedient application of microbial fermentation after whole-wheat milling and fractionation to mitigate mycotoxins in wheat-based products. $L W T$ - Food Science and Technology, 137, art. no. 110440.

hhttps://doi.org/10.1016/j.Iwt.2020.110440
191. Zaunmüller, T., Eichert, M., Richter, H., Unden, G. (2006). Variations in the energy metabolism of biotechnologically relevant heterofermentative lactic acid bacteria during growth on sugars and organic acids. Applied Microbiology and Biotechnology, 72(3), 421-429.

https://doi.org/10.1007/s00253-006-0514-3

192. Zhang, Z., Fan, S., Huang, D., Xiong, T., Nie, S., Xie, M. (2020). Polysaccharides from fermented Asparagus officinalis with Lactobacillus plantarum NCU116 alleviated liver injury via modulation of glutathione homeostasis, bile acid metabolism, and SCFA production. Food \& Function, 11 (9), 7681-7695. https://doi.org/10.1039/D0FO01435D

193. Zheng, J., Wittouck, S., Salvetti, E., Franz, C.M.A.P., Harris, H.M.B., Mattarelli, P., O'Toole, P.W., Pot, B., Vandamme, P., Walter, J., Watanabe, K., Wuyts, S., Felis, G.E., Gänzle, M.G., Lebeer, S. (2020). A taxonomic note on the genus Lactobacillus: Description of 23 novel genera, emended description of the genus Lactobacillus Beijerinck 1901, and union of Lactobacillaceae and Leuconostocaceae. International Journal of Systematic and Evolutionary Microbiology, 70(4), 2782-2858. https://doi.org/10.1099/ijsem.0.004107

194. Zheng, X.-F., Yang, Z., Zhang, H., Jin, W.-X., Xu, C.-W., Gao, L., Rao, S.-Q., Jiao, X. (2020). Isolation of virulent phages infecting dominant mesophilic aerobic bacteria in cucumber pickle fermentation. Food Microbiology, 86, art. no. 103330. https://doi.org/10.1016/j.fm.2019.103330

195. Zhou, C., Li, J., Mao, K., Gao, J., Li, X., Zhi, T., Sang, Y. (2019). Anti-hangover and anti-hypertensive effects in vitro of fermented persimmon juice. CyTA - Journal of Food, 17(1), 960-966. https://doi.org/10.1080/19476337.2019.1680578

196. Zhou, Y., Wang, R., Zhang, Y., Yang, Y., Sun, X., Zhang, Q., Yang, N. (2020). Biotransformation of phenolics and metabolites and the change in antioxidant activity in kiwifruit induced by Lactobacillus plantarum fermentation. Journal of the Science of Food and Agriculture, 100(8), 3283-3290. https://doi.org/10.1002/jsfa.10272

197. Zieliński, H., Honke, J., Topolska, J., Bączek, N., Piskuła, M.K., Wiczkowski, W., Wronkowska, M. (2020). ACE inhibitory properties and phenolics profile of fermented flours and of baked and digested biscuits from buckwheat. Foods, 9(7), art. no. 847. https://doi.org/10.3390/foods9070847

198. Zieliński, H., Szawara-Nowak, D., Wronkowska, M. (2020). Bioaccessibility of anti-AGEs activity, antioxidant capacity and phenolics from water biscuits prepared from fermented buckwheat flours. LWT-Food Science and Technology, 123, art. no. 109051 .

https://doi.org/10.1016/j.lwt.2020.109051 